\title{
Salinity Variability Along the Eastern Continental Shelf of Canada and the United States, 1973-2013
}

\author{
James J. Bisagni \\ University of Massachusetts, Dartmouth \\ School for Marine Science and Technology \\ 200 Mill Road \\ Fairhaven, Massachusetts, 02719 \\ jbisagni@umassd.edu
}

Continental Shelf Research

Revised 1 June 2016 


\begin{abstract}
$\underline{\text { Abstract }}$
Continental shelf waters located off the east coast of Canada and the United States are part of a long shelf current system that is partly comprised of colder, less-saline waters originating from high latitudes, including waters from the North Atlantic sub-polar gyre, along with ice-melt and freshwater input from local rivers. A 41-year analysis (1973-2013) of near-surface salinity (NSS) using three hydrographic datasets (Bedford Institute of Oceanography "Climate", NOAA/ESDIM, and Canadian Marine Environmental Data Service (MEDS)) allowed an examination of NSS variability within 11 continental shelf sub-regions, extending from the southern Newfoundland Shelf of eastern Canada to the DelMarVa/Hatteras Shelf of the United States. Although the periods of record containing sufficient data vary between sub-regions, regional mean NSS values are lowest within the Gulf of St. Lawrence and highest on the DelMarVa/Hatteras shelf, with largest annual variability within the Gulf of St. Lawrence. After removal of outliers, long-term linear trends computed from annual mean NSS were detected along the Newfoundland Shelf $\left(+0.011 \mathrm{y}^{-1}\right)$, Western Scotian Shelf $\left(-0.007 \mathrm{y}^{-1}\right)$, Gulf of Maine ($\left.0.014 \mathrm{y}^{-1}\right)$, Georges Bank (-0.011 $\left.\mathrm{y}^{-1}\right)$, and DelMarVa/Hatteras Shelf $\left(+0.024 \mathrm{y}^{-1}\right)$. A long-term quadratic fit to annual mean NSS from the Eastern Scotian Shelf displays a salinity increase through 1992 of $+0.026 \mathrm{y}^{-1}$, decreasing thereafter until 2013 by $-0.028 \mathrm{y}^{-1}$. A quadratic fit for the Western Grand Banks displays a NSS increase through 2007 of $+0.022 \mathrm{y}^{-1}$, decreasing thereafter through 2013 by $-0.006 \mathrm{y}^{-1}$. Annual mean NSS from the Eastern Grand Banks, Tail of the Grand Banks, Gulf of St. Lawrence, and Middle Atlantic Bight display no long-term trends. Interannual variability (IAV) of NSS residuals shows similar small mean squared error (mse) of 0.020.04 for the four northern-most sub-regions (Newfoundland Shelf, Eastern, Tail and Western Grand Banks) and are correlated at 0-year lag. IAV of NSS residuals (mse) are larger for the Gulf of St. Lawrence ( 0.19), Eastern and Western Scotian Shelf ( 0.09-0.06), Gulf of Maine and Georges Bank ( 0.08-0.06), Middle Atlantic Bight ( 0.19), and maximal for the DelMarVa/Hatteras Shelf ( 0.36), and are also correlated at 0-year lag, but are uncorrelated with the four northern-most sub-regions. Consideration of a simple "flux variation" model that includes along-shelf, altimeter-derived velocity anomalies measured upstream on the Western Scotian Shelf and the positive along-shelf mean salinity gradient between the Eastern Scotian Shelf and the DelMarVa/Hatteras Shelf, may explain the synchronous nature of NSS residuals for the southern-most 6 sub-regions. Furthermore, the flux variation model results in calculated NSS residuals that are within a factor of two of observed NSS residuals for the southern-most DelMarVa/Hatteras Shelf. Co-varying broad-scale coastal sea level and shelf break front position anomalies also support the flux variation model, as do CMV Oleander temperature anomalies across a limited Middle Atlantic Bight shelf region. Overall, the relationships between alongshelf observations of NSS and other shelf parameters support an existing wind-driven dynamical shelf model. Specifically, a flux variation model is able to describe IAV of NSS along a section of the Canadian and U.S shelf for periods greater than one year. In the future, this model may be able to provide useful indices of regime change as noted within the Northeast Shelf Large Marine Ecosystem by other workers.
\end{abstract}




\subsection{Introduction}

The continental shelf located offshore of eastern Canada and the northeastern United States encompasses the large relatively shallow area from the western Labrador Sea to Cape Hatteras, located between the shore and the shelf break inshore of the 200-m isobath). Mean flow of continental shelf waters over this shelf region is generally continuous and equator-ward due to buoyancy-driven currents forced by glacial and ice-melt water from northern sources including Hudson Bay and the Labrador and Newfoundland shelves (Myers et al., 1990). Northern source regions also include the West Greenland Current, southern Greenland, Hudson Strait, and coastal Labrador based on oxygen-isotope data, forming a long coastal current that extends from possibly as far north as Denmark Strait to Cape Hatteras in the south (Fairbanks, 1982; Chapman et al., 1986; Chapman and Beardsley 1989). Thus, shelf waters over this large region are generally less saline and colder than the slope waters located further offshore (Bigelow and Sears, 1935; Wright and Parker, 1976; Beardsley, 1976) and are influenced by both the inshore and offshore branches of the Labrador Current, the western boundary current of the North Atlantic sub-polar gyre located within the Labrador Sea (Smith et al., 1937; Petrie and Anderson, 1983; Peterson, 1987; Greenberg and Petrie, 1988; Lazier and Wright, 1993; Drinkwater, 1996; Loder et al., 2001). The inshore branch of the Labrador Current flows south along the Labrador shelf and through Avalon Channel south of Newfoundland. The offshore branch of the Labrador Current bifurcates at the Flemish Cap with some flow turning eastward, while a second bifurcation occurs at the Tail of the Grand Banks, with a substantial fraction of the transport turning eastward to join the North Atlantic current extension of the Gulf Stream (Petrie and Anderson, 1983). Northeast shelf waters are also influenced by some of the strongest atmospheric forcing in the world (Thompson et al., 1988) with high variability and some recent extreme events (Chen et al., 2014), along with local river discharge. The largest source of freshwater river discharge is the St. Lawrence River, which connects to the northwestern corner of the Gulf of St. Lawrence (GSL). The large discharge from the St. Lawrence River eventually flows onto the Scotian Shelf, with the entire GSL contributing approximately 35\% of the fresh water to the Scotian Shelf (Khatiwala et al., 1999).

The shelf break front (SBF) forms the boundary between shelf waters and the warmer and more saline slope waters located further offshore and is readily detectable year-round over a distance of greater than $2000 \mathrm{~km}$, between the Tail of the Grand Banks $\left(50^{\circ} \mathrm{W}\right)$ and Cape Hatteras $\left(75^{\circ} \mathrm{W}\right)$ using satellite-derived sea surface temperature (SST) (Drinkwater et al., 1994; Bisagni et al., 2006). Given the competing effects of salinity and temperature on seawater density, the SBF is a partly density-compensated oceanographic front that slopes downward from its surface expression towards shore, exhibiting strong hydrographic seasonality (Flagg, 1977; Linder and Gawarkiewicz, 1998). Over more southern regions of this large shelf domain, seasonally-averaged changes of temperature, salinity, and density across the SBF are $5^{\circ} \mathrm{C}$, 2 , and $0.5 \mathrm{~kg} \mathrm{~m}^{-3}$, respectively, with maximum summer cross-frontal gradients and variance confined to sub-surface waters (Garvine et al., 1988, Linder et al., 2006). Using an Ekman slab-layer model, Bisagni et al. (2006) show a clear annual cycle of the SBF surface position, with the SBF located offshore (onshore) during winter (summer) east of $\sim 71^{\circ} \mathrm{W}$. The annual cycle of the extreme western SBF segment (west of $\sim 71^{\circ} \mathrm{W}$ ) is $180^{\circ}$ out of phase from the eastern segment due to the more southerly orientation of the local bathymetry. Hydrographic data from the Nantucket Shoals region (Linder and Gawarkiewicz, 1998) show the near-bottom SBF moving offshore during the February-April period, lagging the seasonal late-fall offshore movement of the surface outcrop of the SBF by about 4 months. Unrelated to Ekman forcing, an annual westward- 
propagating, seaward meander of the SBF occurs between November (at the Tail of the Grand Banks, $50^{\circ} \mathrm{W}$ ) and April (south of Newfoundland, $56^{\circ} \mathrm{W}$ ), corresponding to earlier upstream maximal seasonal transport of the Labrador Current during October near Hamilton Bank (Lazier and Wright, 1993; Bisagni et al., 2006). Inter-annual variability (IAV) of the SBF surface position over the same domain shows alternating periods of westward-propagating offshore (late 1970s, late 1980s, late 1990s) and onshore (early 1980s, early 1990s, early 2000s) annual mean SBF surface position anomalies, thus exhibiting a period of approximately 10 years (Bisagni et al., 2009), possibly related to shelf water volume variations. Moreover, at least from 1977-1999 within the Middle Atlantic Bight (MAB), IAV of the annual mean SBF position does appear related to the MAB-wide mean shelf water volume and salinity anomalies (Mountain 2003), with offshore (onshore) SBF anomalies corresponding to periods with positive (negative) volume and negative (positive) salinity anomalies (Bisagni et al., 2009).

Long-term observational programs within Canadian shelf waters include hydrographic measurements by Canada's Department of Fisheries and Oceans (DFO) for the North Atlantic Fisheries Organization (NAFO) since the early 1970s (Doubleday, 1981) at 100-200 stations per survey, and the Atlantic Zone Monitoring Program (AZMP) from 1998-present, extending from the Newfoundland shelf to the western Scotian Shelf; including the St. Lawrence Estuary and the Gulf of St. Lawrence itself (http://www.meds-sdmm.dfo-mpo.gc.ca/isdm-gdsi/azmp-pmza/indexeng.html). Long-term AZMP monitoring generally consists of 14 repeat (seasonal) hydrographic sections and 7 repeat stations, with some earlier stations (e.g., Station 27 near St. John's, Newfoundland) sampled since the 1970s. Some AZMP sections (e.g., Halifax section) were sampled on a semi-regular basis prior to 1998. Over southern U.S. waters, monitoring of the continental shelf largely began with the early work of Henry Bigelow and the groundbreaking studies within the Gulf of Maine (Bigelow, 1927). Later intensive broad-scale hydrographic surveys were conducted by the National Oceanic and Atmospheric Administration's National Marine Fisheries Service (NOAA/NMFS) from the Gulf of Maine to the southern MAB and completed using stratified random sampling during spring and fall trawl survey program from the 1960s to present. From 1977-1987 the NOAA/NMFS Marine Resources, Monitoring, Assessment and Prediction (MARMAP) program surveyed the entire U.S. shelf region approximately seasonally at over 140 fixed station locations. The MARMAP program was followed by the U.S. Global Ocean Ecosystems Dynamics (GLOBEC) Northwest Atlantic Georges Bank program broad-scale surveys and process cruises (1995-1999) and the NOAA/NMFS Ecosystem Monitoring (EcoMon) program, extending these earlier shelf observational programs to present day.

Present work was motivated by the important role of fresh water for partly controlling vertical hydrographic structure, physical circulation patterns, physical, chemical, and biological processes, and indicating possible climate-related changes in the arctic and their impact within the "downstream" combined Canadian and U.S. Northeast Shelf Large Marine Ecosystem (NESLME). Importantly, salinity has been shown to be a valuable indicator of "regime shifts" (step-like changes) on Georges Bank, a limited region of the NESLME, where strong co-varying changes in both physical and biological properties (zooplankton assemblages and fish recruitment) have occurred, (e.g., Mountain and Kane (2010)). A numerical modeling study has shown that for Georges Bank, salinity is an important indicator influencing the phytoplankton bloom timing and magnitude on the Bank (Song et al. 2010) while observations within the Gulf of Maine show that salinity is the primary determinant of density stratification, dominating surface stratification during winter, spring and fall (Deese-Riordan, 2009). In addition, higher 
inflow of low salinity Scotian Shelf waters is associated with increased winter phytoplankton and zooplankton production in the Gulf of Maine (Durbin et al. 2003; Pershing et al. 2005), which can affect Georges Bank cod and haddock populations (Mountain and Kane, 2010). Further upstream on the Scotian Shelf, higher haddock recruitment during recent years is related to early spring blooms resulting in more copepod prey for fish larvae (Platt et al. 2003; Head et al. 2005). For Georges Bank cod and haddock, greater abundance of their larval prey, Pseudocalanus spp., is associated with greater growth and better survival (Buckley and Durbin, 2006).

Despite the Canadian and U.S. regional monitoring programs described above, a largescale and long-term analysis of salinity variability, encompassing the Canadian and U.S. continental shelf, was needed to examine IAV of shelf-wide, low frequency salinity changes that may be related to observed westward-propagating annual mean SBF surface position anomalies described above. As part of the work reported below, regional mean NSS, along with both annual and inter-annual NSS variability over the entire eastern Canadian and U.S. continental shelf, are examined for 11 nearly contiguous sub-regions beginning with the Newfoundland shelf in the north, southward to the DelMarVa/Hatteras shelf (Fig. 1), over a distance of approximately 2500 km, for a 41-year (1973-2013) period. In addition, both annual and IAV of satellite-derived SBF surface positions are compared with observations of NSS within the 11 sub-regions for the same time period. Lastly, a previously described wind-driven dynamical model is proposed that supports many of the observations of NSS and SBF position variability over large sections of the study domain. 


\subsection{Data \& Methods}

\section{$\underline{2.1 \text { Hydrographic Data }}$}

Hydrographic data for the work presented herein (through January 2010) were obtained from Canada's DFO Bedford Institute of Oceanography (BIO) "Hydrographic Climate” database (Gregory, 2004). The BIO database contains observations from hydrographic bottles, Conductivity Temperature Depth (CTD) profiles, profiling floats, towed transects, and surface measurements, along with near real-time observations from the Global Telecommunications System (GTS). Initially, all data were validated by the originating institution, whether domestic or foreign, and then by Canada's Marine Environmental Data Service (MEDS). Data were subjected to a set of final tests at BIO before being included into the database. Initial data queries to the BIO database through the BIO Climate Application provided the datasets used for the analysis of near-surface salinity described below. The data, along with its validation and extraction methods used for the spatial and temporal data querying, are available from BIO (http://www.bio.gc.ca/science/data-donnees/base/data-donnees/climate-climat-eng.php). Data from February 2010 through December 2013 were obtained directly from Canada's MEDS using the same data methods in a compatible data format and processed in an identical manner as the BIO data, resulting in a continuous data set for the entire 1973-2013 analysis period. An additional data set comprised of approximately 50,000 hydrographic and CTD stations collected prior to 2007 from Russian data sources under a NOAA-funded ESDIM (Environmental Services Data and Information Management) “data rescue” effort were obtained (D. Mountain, pers. comm.) and combined with the BIO data for this analysis. The combined BIO, ESDIM and MEDS 1973-2013 NSS data set contains nearly a half-million $(468,507)$ observations and corresponds to the time period of the newly updated SBF position data set that is re-analyzed and described below. Spatial coverage of salinity observations during the entire 41-year period over the greater continental shelf region (water depths of less than $200 \mathrm{~m}$ ) used in this study is shown (Fig. 2). Partitioning of these data using the 11 sub-regions (Fig. 1) form the basis of the NSS analysis presented below. MEDS data were unavailable for the Gulf of St. Lawrence (GSL) subregion after January of 2010 (Fig. 2); therefore, analysis of GSL salinity was limited to the 19732009 time period.

All salinity measurements were combined for each of the analyses given below through spatial partitioning of the data into the 11 sub-regions (Fig. 1) using the first near-surface measurement located at or above $5 \mathrm{~m}$ depth $(\mathrm{z} \leq 5 \mathrm{~m})$ for each station with bottom depth equal to or less than $200 \mathrm{~m}(\mathrm{H} \leq 200 \mathrm{~m})$. These two depth criteria allowed characterization of NSS and its spatial and temporal variation for the continental shelf waters as defined within our study domain. Regional mean NSS was computed for each sub-region, along with an annual cycle using a least-squares harmonic regression model (Fofonoff and Bryden, 1975) of up to third order (3 cycles per year). Regression modeling was completed iteratively, with the next higher order (shorter period) harmonic being used only if the lower order fit was significant at the 95\% confidence level. The final annual cycle model fit to the data was completed using the same iterative technique after eliminating all data outside of \pm 2 standard deviations of the initial fit, thus eliminating outliers (see Bisagni (1992) for further details). IAV of NSS for each year and for each sub-region was computed as the annual mean of all NSS residuals relative to the harmonic regression value for each measurement's year day of observation. 


\subsection{Shelf Break Front (SBF) Positional Data}

Prior to general availability of digital satellite-derived SST data during the mid-to-late 1980's, the U.S. Naval Oceanographic Office (NAVOCEANO) and NOAA produced weekly Experimental Ocean Frontal Analysis (EOFA) and Gulf Stream Analysis (GSA) charts of SST, respectively, for the western North Atlantic Ocean. Beginning in 1980, NOAA began publishing Oceanographic Analysis (OA) charts three times per week and included coverage eastward to the Grand Banks and the Flemish Cap. Each EOFA/GSA/OA chart depicts the location of the SBF in gridded coordinates based upon analysis of infrared satellite SST imagery. Earlier work has shown the SBF to be usually detectable along its entire length by a trained analyst despite weak horizontal gradients above the seasonal thermocline from late spring through early fall (Halliwell and Mooers, 1979). All weekly charts from 1973-2013 were analyzed at BIO by digitizing the position of the surface SBF along each of 26 longitude lines from $75^{\circ}$ to $50^{\circ} \mathrm{W}$. Monthly-mean SBF positions were then computed along each longitude line between $75^{\circ}$ and $50^{\circ} \mathrm{W}$ for the 41 year period from the weekly data. The monthly-mean SBF positions form the basis of the SBF data analyzed herein for this work as described previously (Bisagni et al., 2006). Digitization errors for the SBF for an individual chart are estimated to be approximately $5 \mathrm{~km}$ (R. Pettipas, pers. comm.). Due to the convoluted nature of the SBF, multiple latitudinal SBF positions along any single longitude line were processed by subtracting the total latitudinal width of shelf water located seaward of the shoreward-most SBF crossing from the shoreward-most SBF position (cf. Figure 2, Drinkwater et al., 1994). SBF positions from any given chart containing regions of cloud cover were estimated based upon the most recent valid prior SBF position.

Monthly-mean BIO surface SBF positions over the 41-year period were converted from latitudinal values along each longitude line to a distance anomaly in kilometers measured from the 41-year mean SBF position (Fig. 3). Positive (negative) SBF position anomalies at each longitude are defined as shoreward (seaward) deviations from the mean SBF position. Longterm, monthly-mean SBF distance anomalies were computed along lines of longitude as the mean of all available (up to 41) individual monthly anomalies for each of the 12 months, yielding the mean annual cycle of SBF positions at each longitude similar to Bisagni et al. (2006). Individual monthly-mean distance anomalies missing for some months at some longitudes are due largely to a lack of data in easternmost regions, with the largest number of missing data located east of $56^{\circ} \mathrm{W}$ (Fig. 4). Inter-annual variability (IAV) of the surface SBF position at each longitude was computed as the annual mean of the 12 monthly anomalies for each year after removal of the mean annual cycle for each month similar to Bisagni et al. (2009).

\subsection{River Discharge Data}

Coastal sources of major freshwater discharges into shelf waters off the U.S. eastern seaboard are examined using United States Geological Survey (USGS) river discharge data from a suite of 7 major rivers, including (from north to south) the St. John, St. Croix, Merrimack, Hudson, Delaware, Susquehanna, and Potomac Rivers. Further north, the Canadian Hydrographic Service's river discharge data, together with data from the St. Lawrence Global Observatory (http://slgo.ca) were used to compute the sum of the discharges from a) St. Lawrence River, b) Saguenay River, and c) the Betsiamites, Outardes, and Manicouagan Rivers, into a single parameter termed "RIVSUM" as discussed by Koutitonsky et al., (1990). See Table 1 for detailed river gauge station information.

Long-term monthly mean discharge values were computed over the same 41-year period (1973-2013) for each river (Fig. 5) and used to examine the mean annual cycles of discharge for 
comparison with the magnitude and phase of the mean annual NSS cycle within 7 of the southern-most sub-regions described above (GSL and south). IAV of annual mean anomalies of discharge from the 8 river sources (including RIVSUM) was computed as the annual mean of the 12 monthly anomalies for each year after removal of the 41-year annual cycle of monthly mean river discharge from Figure 5.

\subsection{Other Ancillary Data}

De-trended annual mean composite coastal sea level anomaly (CSLA) computed from 12 tide gauge stations located within the Scotian Shelf, Gulf of Maine, and Middle Atlantic Bight and reported by Andres et al. (2013) were obtained for the 1970-2012 period for comparison with the primary data sets described above. De-trended, annual mean expendable bathythermograph (XBT) shelf temperatures $\left(T_{s}\right)$ from the CMV Oleander transect (Fig. 3) produced for 1977-2013 by averaging along a common cross-shelf grid between the surface and bottom (5-m vertical resolution) and inshore of the $80-\mathrm{m}$ isobath (10-km horizontal resolution) as reported by Forsyth et al. (2015) were also obtained. Lastly, de-trended along-shelf annual mean velocity anomalies $\left(+\mathrm{v}\right.$ directed towards $\left.70^{\circ} \mathrm{T}\right)$ inferred from satellite altimeter-derived sea surface height anomalies were obtained for 1993-2008 along cross-shelf section S1 directed southeast of Cape Sable, Nova Scotia (Fig. 3) as described by Li et al. (2014). 


\subsection{Results}

\subsection{NSS Regional Means \& Annual Variability}

Regional mean NSS values for each of the 11 sub-regions are shown (Fig. 6, Table 2), along with the minimum and maximum NSS values from each sub-region's harmonic regression annual cycle model, and the year day of occurrence for each extremum. Regional mean NSS values are lowest within the GSL (30.49) and highest on the DHS (32.72). Regional mean NSS values increase rapidly from the GSL to the northeast, but less rapidly to the southwest, with a local maximum (minimum) at the TGB (MAB). Annual NSS variability is also largest within the GSL $(\Delta S \sim 2.5)$, with large annual variability also occurring on the NFS ( $\Delta S \sim 1.9)$, MAB $(\Delta S$ $\sim 2.0$ ), and DHS ( $\Delta S \sim 2.3$ ) shelves (Fig. 6). Negative (positive) NSS anomalies are largest from late summer through fall, day 250-298, (late winter through spring, day 58-139) from the NFS through the WGB with a reduction in magnitude and a progressively later phase to the west, suggesting possible along-shelf propagation from east to west for these four eastern-most subregions (Figs. 6, 7).

The GSL shows the largest negative (positive) NSS anomaly occurring during early fall on day 274 (during late spring on day 79) with a strong reduction in magnitude and later phase for both extrema upon reaching the ESS, suggesting possible dilution and propagation of annual salinity anomalies from the GSL to the ESS (Figs. 6, 7). The WSS, GOM, and GB exhibit increasing regional mean NSS values (Fig. 6) towards the west, with nearly equivalent annual NSS variability but increasingly complex timing of the extrema between the three sub-regions (Fig. 7). The WSS sub-region exhibits a primary NSS maximum during winter (day 50) and a primary minimum during summer (day 203), with a reduced secondary maximum (day 276) and minimum (day 339), during early and late fall, respectively (Figs. 6, 7). Along the less complex MAB and DHS shelves, the regional mean NSS increases to the south and west, with much larger, and nearly equal annual cycles, that display later phasing at the MAB relative to the DHS (Figs. 6, 7), with strong minima (maxima) occurring during early summer (early winter).

\subsection{Long-Term Trends and NSS Inter-Annual Variability (IAV)}

Annual mean NSS values are shown over the period of record for each of the 11 shelf sub-regions (Fig. 8), along with the lowest order model trend (Table 2) that is significant $(\mathrm{p} \leq 0.05)$. The time series mean is used if neither a linear nor quadratic model is valid. After removal of any outliers, significant long-term linear trends of NSS were detected on NFS $\left(+0.011 \mathrm{y}^{-1}\right)$, WSS $\left(-0.007 \mathrm{y}^{-1}\right)$, GOM $\left(-0.014 \mathrm{y}^{-1}\right)$, GB $\left(-0.011 \mathrm{y}^{-1}\right)$, and DHS $\left(+0.024 \mathrm{y}^{-1}\right)$. A long-term quadratic fit of NSS from the ESS displays a salinity increase through 1992 of 0.52 $\left(+0.026 \mathrm{y}^{-1}\right)$, decreasing thereafter until 2013 by $\sim 0.59\left(-0.028 \mathrm{y}^{-1}\right)$. A long-term quadratic fit for WGB displays a NSS increase through 2007 of $\sim 0.59\left(+0.022 \mathrm{y}^{-1}\right)$, decreasing thereafter until 2013 by $\sim 0.034\left(-0.006 \mathrm{y}^{-1}\right)$, but contains only one data point prior to 1992 . Annual mean NSS values from the EGB, TGB, GSL, and MAB displayed no long-term linear or quadratic trends.

Annual mean NSS residuals were computed over the period of record for each of the 11 shelf sub-regions by subtraction of the yearly values of the fitted corresponding trend (or mean) from the annual mean NSS values. North-to-south plotting of the NSS residuals using an offset plotting technique (each successive plot is offset along the ordinate by 1 PSU) allows a visual comparison of the phase and magnitude of the IAV of NSS residuals between the 11 sub-region time series (Fig. 9). North-to-south differences in the magnitudes of the annual mean NSS residuals are large (Table 2) with similar small mean squared error (mse) of $\sim 0.02-0.04$ (relative 
to each sub-region's respective model fit or mean value) for the four northern-most sub-regions (NFS, EGB, TGB, and WGB) and appear to be temporally coherent. IAV of mse for NSS residuals is larger for the GSL ( 0.19), ESS, and WSS ( 0.09-0.06), GOM and GB ( 0.08-0.06), MAB ( 0.19), and maximal for DHS ( 0.36) (Table 2), with coherent temporal fluctuations between these more southern 7 sub-regions (Fig. 9). Despite some missing data prior to 1992, fluctuations clearly increase in magnitude after 1990 within these more southern 7 sub-regions, with fluctuations (mse values) increasing steadily to the south as given in Table 2. Furthermore, comparison of the magnitudes and phases of IAV of annual mean NSS residuals for the four southern-most sub-regions (GOM, GB, MAB and DHS) from this study with surface salinity anomalies computed using individual NOAA/NMFS cruises for the nominal 1977-2013 period, (MARMAP, 1977-1987; spring and fall survey cruises, and EcoMon data through 2013) show good agreement (Fig. 9). Thus, despite the large-scale spatial compositing and annual temporal averaging of NSS data used in this study, the nominal 41-year record of NSS residuals provides a valid dataset to examine long-term IAV of NSS over the entire Canadian and U.S. NESLME for periods greater than one year.

After elimination of outliers and accounting for autocorrelation effects, computation of cross-correlations of NSS residuals between all 11 sub-regions at lags of 0,1 , and 2 years supports what is readily apparent between NSS residual time series (Fig. 9). Results show that the largest number of significant cross-correlations occur at a lag of 0 years (Fig. 10a), with the four northern-most sub-regions (NFS, EGB, TGB and WGB) displaying significant correlations of 0.4-0.5 between them and GSL, but displaying overall decreases in cross-correlations south of GSL with the remaining six sub-regions. Cross-correlations at a lag of 0 years are also generally high and significant among the six southern-most sub-regions (ESS, WSS, GOM, GB, MAB and DHS), especially between contiguous sub-regions, e.g., ESS \& WSS and MAB \& DHS, (Fig. 10a). At lags of 1 and 2 years (Figs. 10b, 10c) results show much fewer significant cross-correlations between all sub-regions, supporting the occurrence of simultaneous, highly correlated NSS fluctuations, between all sub-regions within each of the two groups of 4 northern-most and 6 southern-most sub-regions. Given the effect of the very large annual freshwater discharge from the Gulf of St. Lawrence (Fig. 5), the generally high cross-correlation values at a lag of 0 years between GSL and the surrounding sub-regions is expected (Fig. 10a).

\subsection{Shelf Break Front (SBF) Position: Annual \& Inter-Annual Variability (IAV)}

The long-term, 41-year (1973-2013) annual cycle of monthly mean SBF surface position anomalies is shown (Fig. 11) using all available monthly mean anomaly values (Fig. 4) along 26 longitude lines between $50^{\circ}$ and $75^{\circ} \mathrm{W}$. Overall, the SBF annual cycle shows the SBF to be located largely offshore (onshore) relative to its regional mean position (Fig. 3), from $50^{\circ}$ to $72^{\circ}$ $\mathrm{W}$ for the 6-month period of December - May (June - November) of each year. Similar to observations from an earlier analysis by Bisagni et al. (2006) for the shorter 1973-2001 period, a nearly $180^{\circ}$ phase shift in the annual cycle occurs beginning near $70^{\circ} \mathrm{W}$, with offshore (onshore) SBF positions from April - July (January-March). Furthermore, between $50^{\circ}$ to $57^{\circ} \mathrm{W}$, a strong westward-propagating offshore SBF feature is prominent in the record for the 1973-2013 analysis period (Fig. 11), entering at $50^{\circ} \mathrm{W}$ during November (yearday 318), and moving steadily westward at $3.2 \mathrm{~km} \mathrm{~d}^{-1}\left(\sim 0.04 \mathrm{~m} \mathrm{~s}^{-1}\right)$ to $57^{\circ} \mathrm{W}$ by April (yearday 470 ) as reported earlier by Bisagni et al. (2006).

The IAV of annual mean SBF surface position for the 41-year (1973-2013) period of record (Fig. 12) displays alternating positive and negative bands of westward-propagating SBF 
anomalies as reported earlier by Bisagni et al. (2009) for the 1973-2001 period. Despite some missing data located largely between $50^{\circ}$ to $55^{\circ} \mathrm{W}$ from 1973-1977 and 1996-2004, the longitude-time plot reveals alternating bands of offshore (late 1970s, late 1980s, late 1990s, late 2000s) and onshore (early 1980s, early 1990s, early 2000s, early 2010s) annual mean SBF anomaly values, thus exhibiting a period of approximately 5-10 years. Overall, the largest anomalies are located near $55^{\circ} \mathrm{W}$, with the alternating temporal bands appearing less welldefined beginning during 2005. Speed calculations for the westward-propagating features yielded a value of approximately 1.2 to $2.4 \mathrm{~cm} \mathrm{~s}^{-1}$ ( 1 to $2 \mathrm{~km} \mathrm{~d}^{-1}$ ), with annual mean SBF anomalies thus requiring about 3 years to propagate from the Tail of the Grand Banks $\left(50^{\circ} \mathrm{W}\right)$ in the northeast to Cape Hatteras $\left(75^{\circ} \mathrm{W}\right.$ ) in the southwest (Bisagni et al., 2009).

\subsection{Cross-Correlation Analysis of IAV of Along-Shelf Properties}

Given the broad-scale equator-ward mean current patterns on the Canadian and U.S. northeast continental shelf, along with the evidence presented above, it is intriguing to consider that IAV of both NSS and SBF anomaly patterns are caused by advection of southwestward propagating signals along the entire northeast Canadian and U.S. shelf. However, the synchronous nature of NSS IAV anomalies along nearly the entire continental shelf (Fig. 9), along with the very slow propagation speeds of inter-annual SBF surface position anomalies, together do not seem to support a simple advective model of these properties on inter-annual time scales. Cross-correlations between long-term records of various other shelf properties for the period of the 1970s through 2010s are presented below to examine the relationships between shelf properties and to identify a plausible model to explain the results of the correlation analysis.

\subsection{SBF Anomaly and NSS Residual}

Earlier work (Bisagni et al., 2009) suggested that a relationship might exist between annual mean SBF position anomalies and annual mean salinity anomalies within the Middle Atlantic Bight. This relationship is further examined herein through a cross-correlation analysis for a subset of 7 sub-regions, including TGB, WGB, ESS, WSS, GB, MAB, and DHS. Annual mean SBF position anomalies along assigned measurement longitudes corresponding to each of the 7 sub-regions were averaged and cross-correlated with annual mean NSS residuals for each sub-region. The assigned SBF measurement longitudes corresponding to each sub-region, together with the cross-correlation and p values are given (Table 3). The corresponding SBF and NSS time series are also shown for the 7 sub-regions (Fig. 13).

Results show no relationship (Table 3) between the averaged SBF anomaly and NSS residual for the four northern-most sub-regions (TGB, WGB, ESS, and WSS), although a qualitative similarity does exist between the two data sets after 1992 (Fig. 13). However, for the three southern-most sub-regions (GB, MAB and DHS), two of the three (GB and DHS) display highly significant cross-correlation coefficients. It is surprising that the intervening MAB subregion does not exhibit a similar significant correlation to that suggested by Bisagni et al. (2009) for this longer analysis period. The earlier comparison averaged the SBF position anomalies over a larger range of longitudes $\left(70^{\circ}-75^{\circ} \mathrm{W}\right)$ for the shorter $1975-1999$ period used for the salinity anomaly analysis of Mountian (2003). It is worth noting that both the SBF anomaly and NSS residual values do exhibit some readily observable synchrony for the latter half of the time series, especially within the 1995-2000 period for WSS, GB, MAB and DHS, when negative (offshore) SBF anomalies appear highly correlated with periods of negative salinity residuals (Fig. 13). 


\subsection{Along-Shelf Velocity Anomaly and NSS Residual}

The broad-scale, equator-ward, along-shelf flow on the entire northeast continental shelf and recent work by Li et al. (2014) showing its modulation by along-shelf wind stress suggest that an examination of the correspondence between annual mean NSS residuals and along-shelf annual mean velocity anomalies may be warranted. Li et al. (2014) have shown that satellite altimeter-derived cross-shelf sea surface slope anomalies, driven by along-shelf wind stress can result in along-shelf current anomalies through:

$$
v=\frac{g}{f} \frac{\partial \eta}{\partial x}
$$

after removal of the mean, where: $v$ is the near-surface along-shelf velocity, $g$ is the acceleration of gravity, $f$ is the Coriolis parameter and $\partial \eta / \partial x$ is the cross-shelf sea surface slope. Comparison of 16 years (1993-2008) of annual mean $v$ anomalies computed along altimeter section S1 (see Fig. 3 for location) with annual mean NSS residuals (Fig. 14) show significant $(p \leq 0.05)$ crosscorrelation at 0-year lag for GB, MAB, and DHS sub-regions, while the correlations for upstream sub-regions ESS, WSS and GOM, although increasing to the southwest, are either not highly significant ( $\leq 0.09$ for GOM) or insignificant (Table 4). However, despite the variations in cross-correlation, the relationship between along-shelf velocity anomalies and NSS residuals appears robust and synchronous for GB, MAB, and DHS, i.e., throughout most of the region located downstream of the WSS sub-region where section S1 is located, spanning a distance of approximately $1000 \mathrm{~km}$.

\subsection{Oleander Shelf Temperature Residuals and NSS Residuals for the MAB Sub-Region}

Since 1977, expendable bathythermograph (XBT) temperature profiles have been collected approximately monthly from the CMV Oleander, a container ship operated by Bermuda Container Lines, which traverses weekly between Elizabeth, New Jersey, and the island of Bermuda. Through 2013, XBT data were collected as part of NOAA's Northeast Fisheries Science Center (NOAA/NEFSC) Ship of Opportunity Program (SOOP). Despite the NOAA/NEFSC Program being cancelled during December 2013, by mid-2014 the XBT data collection resumed and shifted to the National Science Foundation-sponsored "Oleander Project", a companion effort that also uses hull-mounted ADCPs to record upper-ocean velocities during the CMV Oleander crossings (Flagg et al., 1998; Rossby et al., 2010; Worst et al., 2014). Vertical (5 m) and horizontal (10 km) averaging of all gridded temperature profiles from a synthetic transect along a distance of $130 \mathrm{~km}$ measured from the $40-\mathrm{m}$ isobath were used to produce annual mean temperature residuals $\left(T_{s}{ }^{\prime}\right)$ for the MAB sub-region after removing the 37-year warming trend of $0.026{ }^{\circ} \mathrm{C}^{-1}$ as described by Forsyth et al. (2015).

Comparison of 37 years (1977-2013) of MAB annual mean temperature residuals computed along the CMV Oleander section (see Fig. 3 for location) with annual mean NSS residuals (Fig. 15) shows good correspondence overall despite some missing NSS values, with a maximum significant cross-correlation at 0 -year lag of $r=0.3918$ ( $p \leq 0.0241$ ) (Table 5). Thus, the co-occurrence of less-saline (more-saline) and colder (warmer) shelf conditions within the MAB sub-region along the Oleander section is significant, especially during the 1992-1999 when the two signals correspond exceptionally well. However, correspondence between $T_{s}{ }^{\prime}$ and 
NSS after 2001 appears less robust, with changes in NSS residuals not correlated with changes in $T_{S}{ }^{\prime}$, e.g., after the anomalously warm 2012 (Chen et al., 2014) $T_{s}{ }^{\prime}$ decreased by $\sim 1^{\circ} \mathrm{C}$, while NSS continued to increase despite southward along-shelf advection of colder water from the GOM during 2012 (Chen et al., 2015). Additional work will be needed to resolve such discrepancies. 


\subsection{Coastal Seal Level Anomalies and NSS Residuals for the MAB Sub-Region}

Annually averaged sea level measured using 12 tide gauges along the east coast of the U.S. and Canada from 1970-2012 shows that coastal sea level anomalies (CSLA) are coherent from coastal Nova Scotia to Cape Hatteras, North Carolina (Andres et al., 2013). Furthermore, using satellite altimeter data, the same workers showed that IAV of sea level extended across the shelf for the Middle Atlantic Bight, Gulf of Maine, and Scotian Shelf to the shelf break where a local minimum in sea level variability occurred and was coherent with the composite CSLA anomaly. The shelf sea level response appeared to be related to along-shelf winds for the period of study, with southward transport anomalies likely being diverted offshore at Cape Hatteras and re-circulated into the Gulf Stream (Andres et al., 2013).

Comparison of 40 years (1973-2012) of annually averaged composite CSLA from the 12 tide gauges reported by Andres et al., (2013), when cross-correlated with corresponding NSS residuals for the MAB from this study (Fig. 16) shows an inverse and significant maximum cross-correlation at 0 -year lag of $r=-0.5228$, ( $p \leq 0.0021)$ (Table 5). Thus, the co-occurrence of less-saline (more-saline) shelf conditions across the large MAB sub-region with positive (negative) composite CSLA values is significant, especially beginning during the 1990s until 2012 when the two signals correspond exceptionally well.

3.9 Coastal Seal Level Anomalies and CMV Oleander Shelf Temperature Residuals for the MAB Sub-Region

Comparison of the annually averaged composite CSLA from the 12 tide gauges along the east coast of the U.S. and Canada reported by Andres et al., (2013), when cross-correlated with corresponding $C M V$ Oleander shelf temperature residuals for the MAB shows a strong positive correlation of $r=0.5555$, ( $\mathrm{p} \leq 0.0005$ ) (Table 5) at a lag of +2 -years as reported previously by Forsyth et al. (2015). The +2-year lag is especially interesting given the strong negative crosscorrelation noted above computed between the same CSLA values and NSS residuals at 0-year lag. While results from additional or future work may reveal the cause of this relationship at a lag of +2 years, currently, the cause is unknown. 


\subsection{Discussion}

\subsection{Mean and Annual Variability Patterns of NSS and SBF Position}

The regional mean NSS pattern across a large section of the Canadian and U.S. eastern continental shelf (Fig. 6) displays the effects of freshwater inputs from northern sources, e.g., the Labrador Current and melting of sea ice, supplying freshwater to the eastern Newfoundland shelf (NFS), along with major river inputs of freshwater (Fig. 5) to more southern sub-regions such as the Gulf of St. Lawrence (GSL), Middle Atlantic Bight (MAB) and DelMarVa/Hatteras shelf (DHS). Given these sources of fresh water, the large range of mean NSS (>2.0) over the study domain is expected and in agreement with previous studies of broad-scale shelf NSS patterns and inputs from fresh water sources (Loder et al. 1998; Loder et al. 2001), displaying a similar range across all sub-regions during both winter and summer. The minimum mean NSS value for GSL is not surprising, given the clear dominance of the magnitude of RIVSUM discharge within the GSL relative to other rivers located farther to the south. The mean position of the SBF is located just offshore of the 200-m isobath from Cape Hatteras to central southern Georges Bank where it veers to a maximum offshore position approximately $200 \mathrm{~km}$ south of the Laurentian Channel near $56^{\circ} \mathrm{W}$ and close to the 4000-m isobath (Fig. 3) in agreement with earlier studies (Drinkwater et al., 1994; Bisagni et al. 2006).

Over the annual cycle, both the timing and magnitude of the annual variations of NSS show a prevalence of late spring to summer minima associated with each river's spring freshet (Fig. 5) for the more southern sub-regions (Fig. 7) as far north as the western Scotian Shelf (WSS) in agreement with Loder et al. (1998). Further north, from GSL to NFS, NSS minima appear associated with late summer and fall periods when fresh water from sea ice melt and coastal runoff travels downriver and maximum southward Labrador Current transport occurs, with a later phase further downstream as reported by Sutcliffe et al. (1976). Clear evidence of sequential southwestward propagation of NSS minima is shown beginning during late summer for NFS and propagating to the western Grand Banks (WGB) by mid-late fall of each year (Fig. 7). The late summer NSS minimum for GSL agrees with the maximum spring RIVSUM discharge (Fig. 5), with decreasing salinities beginning during May, propagating through the Eastern Scotian Shelf (ESS) by fall to form a second lesser NSS minimum for WSS by late fall/winter (Fig. 7). This secondary minimum is in near agreement with salinity observations for the primary early winter salinity minimum at a depth of $15 \mathrm{~m}$ at mooring $\mathrm{C} 2$ on the extreme western WSS near Cape Sable and the advection velocity of $6 \mathrm{~km} \mathrm{~d}^{-1}$ reported by Smith (1989). More recently, regional modeling results show that 100 days are required for the May RIVSUM discharge maximum to spread throughout the GSL in agreement with NSS results from this study. An additional 120 days are needed for the same maximum to reach the entrance to the GOM near Cape Sable, in agreement with Smith’s (1989) results (Ohashi et al., 2013). Further downstream, the late spring NSS minimum for the GOM translates to Georges Bank (GB) during summer of each year in agreement with local river runoff and establishment of the annual summertime anti-cyclonic gyre and eastward flow of the western Gulf of Maine coastal current east of Cape Cod. For the most southern sub-regions (MAB and DHS), the strong late springsummer NSS minima (Fig. 7) are clearly related to the occurrence of spring freshets of the combined Hudson, Delaware, Susquehanna, and Potomac Rivers (Fig. 5) to these two continental shelf sub-regions.

Aside from the seasonal Ekman wind-driven response of the SBF described above and by Bisagni et al. (2006), a strong westward-propagating offshore SBF feature (Fig. 11) is shown entering the domain in the east at $50^{\circ} \mathrm{W}$ during November (yearday 318). This feature moves 
steadily westward at $3.2 \mathrm{~km} \mathrm{~d}^{-1}\left(\sim 0.04 \mathrm{~m} \mathrm{~s}^{-1}\right)$ to $57^{\circ} \mathrm{W}$ by April (yearday 470 ) as reported. The timing of this late fall feature is likely related to a shelf water volume maximum resulting from the annual transport maximum of the lower salinity Labrador Current during September-October of each year (Lazier and Wright, 1993) as reported by Bisagni et al. (2006). This conclusion is also supported by the annual NSS minimum, shown herein to occur from late August-early October for the NFS region (Fig. 7) and propagating to WGB by late fall. This relationship provides strong evidence that the SBF is responding seasonally to the annual increase in transport of lower salinity Labrador Current water from the Labrador Sea.

\subsection{Long-Term Trends and Inter-annual Variability (IAV) of NSS}

NSS trends for the 11 sub-regions vary widely, and despite data limitations, show some consistency between sub-regions (Fig. 8, Table 2). Off eastern Newfoundland (NFS) the linear NSS trend is significant and positive, but there are few data prior to 1992 that are able to adequately provide annual mean NSS values before 1992. Data are also sparse for the Grand Banks, with no apparent trend for the EGB and TGB sub-regions. The apparent increase in NSS for WGB through 2007 and decrease thereafter is similar to that for the ESS where salinity increased through 1992, but decreased thereafter; however, data are more plentiful for ESS. Further to the west, the WSS, GOM, and GB sub-regions show significant, long-term linear trends of decreasing salinity, with very few missing data points over the 41-year period of record.

The overall pattern of NSS trends noted above for the Newfoundland Shelf (NFS), Grand Banks (EGB, TGB and WGB), Scotian Shelf (ESS and WSS), and Georges Bank and the Gulf of Maine (GB and GOM) are in general agreement with recent estimates of Labrador Current transport computed using along-track satellite altimeter data and the North Atlantic Oscillation (NAO) as reported by Han et al. (2014). Unit-depth surface transport of the less-saline and colder Labrador Current along the shelf edge displayed a decreasing trend of $1400 \mathrm{~m}^{2} \mathrm{~s}^{-1} / \mathrm{decade}$ over the 20-year period (1992-2012) for the Labrador and Newfoundland shelves within the western Labrador Sea. Further to the southwest along the Scotian Slope, an increasing trend in Labrador Current transport of $1280 \mathrm{~m}^{2} \mathrm{~s}^{-1}$ /decade occurred over the same 20-year period when the NAO winter index exhibited decreasing values. The decrease in Labrador Current transport noted by Han et al. (2014) is consistent with findings of other workers over a similar period that also show a general weakening of the sub-polar gyre (Han and Tang, 2001; Hakkinen and Rhines, 2004; Han et al., 2010). While the positive linear trend of NSS for NFS may result from decreased Labrador Current transport from 1992-2012, similar Labrador Current transport estimates are unavailable prior to 1992. Furthermore, the change to no significant NSS trend over portions of the Grand Banks (EGB and TGB), followed by quadratic trends that display a change from positive to negative NSS trends in the latter part of the time series for WGB and ESS subregions, are in agreement with the Grand Banks being a transition region to increasing westward penetration of the Labrador Current from 1992-2012 as reported by Han et al. (2014).

Farther to the southwest, the significant negative linear NSS trends apparent for the WSS, GB, and GOM sub-regions are consistent with increased transport and westward penetration of the Labrador Current south of the Scotian Shelf (Han et al., 2014). Thus, for the latter half of the 1973-2013 period used for computation of long-term trends in annual mean NSS reported herein, long-term trends over a large portion of the NESLME appear related to changes in Labrador Current transport, are associated with the state of the North Atlantic Oscillation, and are out of phase between the Labrador Shelf and the Scotian Shelf and Gulf of Maine regions. More 
specifically, increased transport within the inshore branch of the Labrador Current may be responsible for the increased Scotian Shelf water transport into the Gulf of Maine during the late 1990s noted by Smith et al. (2001) near Cape Sable, Nova Scotia, increasing up to an additional 40\% during the 2004-2008 period (Deese-Riordan, 2009; Smith et al., 2012). Further to the southwest, the MAB and DHS sub-regions display no significant trend and a strongly positive linear trend, respectively, thus transitioning again to a region where changes in the sub-tropical gyre and Gulf Stream may become dominant as suggested by an increase in the mapped sea height anomalies (Han et al., 2014).

The GSL sub-region, although not part of the contiguous Canadian and U.S. continental shelves, displayed no long-term trend of NSS. However, long-term, annual mean RIVSUM discharge values display a significant $(\mathrm{p} \leq 0.001)$ negative trend of $-430 \mathrm{~m}^{3} \mathrm{~s}^{-1}$ per decade for the 41-year (1973-2013) period of record, or a decrease of $1,763 \mathrm{~m}^{3} \mathrm{~s}^{-1}$ over the period, equal to about a $14 \%$ decrease in discharge relative to the long-term mean value of $12254.1 \mathrm{~m}^{3} \mathrm{~s}^{-1}$ computed for the 1973-2013 period. While a rigorous freshwater budget model of the Gulf of St. Lawrence is beyond the scope of this work, the lack of a long-term increase in NSS for the GSL would require additional freshwater from an alternate source. More specifically, it is possible to speculate that increased transport from the inshore branch of the Labrador Current into the GSL through the Strait of Belle Isle or Cabot Strait may be responsible for the "missing" freshwater transport into the Gulf of St. Lawrence.

Removal of the corresponding NSS trends (or means) from annual mean NSS values for each sub-region resulted in a spatial suite of annual mean NSS residuals for the nominal 19732013 period, spanning just over four decades. The good agreement between a subset of annual mean NSS residuals and the MARMAP surface salinity data already noted (Fig. 9) supports use of these data as valid for studying IAV of NSS over the study region. In addition, comparison of NSS residuals from this study with annual sea surface salinity anomalies for the Newfoundland Shelf, Gulf of St. Lawrence, Scotian Shelf and Gulf of Maine, provided by Li et al. (2014) show strong correspondence between the two data sets, with negative (positive) salinity fluctuations during the early 1980s, mid 1990s, and mid-late 2000s (late 1970s-early 1980s, late 1980s-early 1990s, early 2000s).

A detailed examination of the IAV of NSS residuals for each sub-region from this study (Fig. 9) reveals two distinct zones of NSS residuals; the first located northeast of the Laurentian Channel where the mse of the salinity residuals vary between approximately 0.03-0.04 (Table 2), and the second located southwest of the Laurentian Channel where mse values are much larger (0.10-0.30) as noted above. Moreover, fluctuations of NSS residuals appear to be coherent at 0year lag within each of the two zones (Fig. 9), exhibiting significant positive cross-correlation values across each zone (Fig. 10). Significant positive cross-correlations are almost non-existent within each zone at 1-year and 2-year lags. This overall pattern supports the existence of two distinct regions in agreement with the work of Han et al. (2014), thus describing NSS changes related to the phase structure of the offshore branch of the Labrador Current. Further inshore, Petrie (2007) showed penetration of warmer and more saline bottom waters (colder and less saline) onto the Labrador, Newfoundland and eastern Scotian Shelves and the Gulf of St. Lawrence (western Scotian Shelf and Gulf of Maine) between 1970 and 2004 during periods of negative NAO anomalies. Periods of positive NAO anomalies resulted in the opposite response for these same shelf regions. NSS residual results from this study and Petrie's (2007) analysis of bottom temperatures and salinities are in agreement for the existence of the two zones, and further support the phase differences of the Labrador Current noted by Han et al. (2014) between 
the northern and southern zones. NSS residuals from the Gulf of St. Lawrence exhibit a significant negative cross-correlation ( $\mathrm{r}=-0.6032$; $\mathrm{p} \leq 0.0003)$ with annual mean RIVSUM discharge anomalies at 0 -year lag, i.e., higher RIVSUM discharge generally corresponding to a more negative NSS residual (Fig. 17).

\subsection{A Possible Shelf Model for IAV of NSS}

The strong visual coherence between IAV of the annual mean NSS residuals (Fig. 9) and their significant positive cross-correlations at 0-year lag for sub-regions contained within the northern and southern zones (Fig. 10) is compelling. Moreover, the along-shelf scale of such correspondence is intriguing given the overall size (approx. $2000 \mathrm{~km}$ ) of the combined Canadian and U.S. shelf between $50^{\circ}$ and $75^{\circ} \mathrm{W}$ and the well-known advective and linked nature of their circulation (e.g., Chapman and Beardlsey, 1989). Most prominently: 1) NSS residuals are clearly in phase between the ESS sub-region and the southern-most DHS sub-region (Fig. 9), over a distance of approximately $1400 \mathrm{~km}\left(60^{\circ} \mathrm{W}\right.$ to $\left.75^{\circ} \mathrm{W}\right)$, and 2) NSS residuals (mse) increase by at least a factor of four over this distance (Table 2). However, such coherence across such a large distance is also puzzling given the very slow propagation speeds $\left(0.02-0.03 \mathrm{~m} \mathrm{~s}^{-1}\right)$ of $1970 \mathrm{~s}$ and 1990s salinity anomalies noted upstream for the Labrador Sea (Houghton and Visbeck, 2002) and related westward propagation of annual mean SBF anomalies (Fig. 12) between the Grand Banks and Cape Hatteras (Bisagni et al., 2009). Such slow propagation of Labrador Sea salinity and SBF anomalies for the current study region, would result in a distance traveled of only 600$900 \mathrm{~km} \mathrm{y}^{-1}$ or less than half the required distance. On the contrary, mean current speeds on the combined Canadian and U.S. shelves of $0.05-0.10 \mathrm{~m} \mathrm{~s}^{-1}$ with the higher values offshore (Hannah et al., 2001; Lentz, 2008) are sufficiently-large to cross a distance of over $2000 \mathrm{~km}$ in one year, resulting in the positive 0-year lag cross-correlations of annual mean NSS residuals across the entire region as noted above. Consideration of additional along-shelf data sets described above (river discharge, SBF position, coastal sea level, along-shelf velocity, shelf temperature, and higher frequency hydrographic data) together with recent work by others describing simplified shelf models are discussed below to help provide some insight into the spatial and temporal behaviors of NSS residuals from this study.

Surface salinity anomalies computed using higher frequency, individual NOAA/NMFS cruises for the nominal 1977-2013 period (Fig. 18) for the eastern and western Gulf of Maine, Georges Bank, and the northern and southern Middle Atlantic Bight show a very high degree of low-frequency, temporal coherence on a regional scale in agreement with Mountain and Manning (1994), Mountain and Taylor (1998), and Mountain (2003). Furthermore, surface salinity variability appears to increase southward, in agreement with mse values from this study (Table 2) with some of the largest values occurring for the NOAA/NMFS southern Middle Atlantic Bight region, which is largely congruent with the DHS sub-region from this study. Overall, the NOAA/NMFS surface salinity anomalies support the occurrence of low-frequency surface salinity changes that occur over the large spatial $(\sim 1000 \mathrm{~km})$ and long temporal $(>1$ year) scales reported herein using annual mean NSS residuals. However, unlike this study that utilizes long-term means or linear and quadratic models to compute NSS residuals, NOAA/NMFS surface salinity anomalies were computed using the 1977-1987 MARMAP period for comparison, resulting in non-zero means for data after 1987 and values that are consistently less-saline than annual mean NSS values computed in this study (Fig. 9). Finally, while the two data sets are not independent, the NOAA/NMFS surface salinity anomalies do not show strong 
higher frequency variability relative to the annual mean NSS residuals from this study, tracking the annual mean NSS plots for the four southern-most sub-regions rather well.

The analysis of Li et al. (2014) shows significant wind modulation of sea level slope resulting in IAV of along-shelf current velocity anomalies on the Canadian and U.S. shelf. Stronger northeastward winds were shown to resist the general southwestward, buoyancy driven flow, while weaker northeastward winds favored a stronger southwestward flow. The correspondence of their along-shelf velocity anomalies with NSS residuals from this study (Fig. 14) is clearly in agreement with their sea surface salinity anomalies from the Newfoundland Shelf, Gulf of St. Lawrence, Nova Scotian Shelf, and Gulf of Maine that co-varied with alongshore wind stress anomalies from Sable Island: larger northeastward (southwestward) wind stress anomaly values corresponded to periods of higher (lower) salinity within all four of their regions. However, the present work extends the analysis to three, more-southern sub-regions located south of the GOM (GB, MAB and DHS), comparing annual-mean NSS residuals directly with the annual mean along-shelf velocity anomalies of Li et al. (2014). Results show highly significant cross-correlation values of $r=\sim 0.6$ for all three southern sub-regions, with a lesser value for the GOM of $r=\sim 0.5$ (Table 4). The lack of significant correlation between along-shelf velocity anomalies and NSS residuals for the ESS sub-region may not be unexpected given that ESS is located upstream of altimeter section S1, with section S1 located within the WSS subregion itself.

Sundby and Drinkwater (2007) discuss mechanisms causing North Atlantic salinity anomaly signals from the broader viewpoint of a continuum of salinity anomalies, i.e., anomalies of varying magnitudes and of both negative and positive signs. Of interest is their contrast between two differing salinity anomaly mechanisms that produce identical results: "patch advection" of a near-surface low-salinity pool of water passing through a fixed hydrographic station, and "flux variation in a salinity gradient" where a spatial salinity gradient is advected to and fro by a change in velocity (flux) at a fixed hydrographic station (Fig. 19); with both mechanisms producing identical "low salinity anomalies". Their discussion focused on how such a "flux variation" mechanism better supports the Great Salinity Anomalies noted during the 1970s (Dickson et al., 1988), the 1980s (Belkin et al., 1998), and 1990s (Belkin, 2004). Given the overwhelmingly large freshwater discharge into the GSL from the RIVSUM source (Fig. 5) and the GSL minimum mean salinity (Fig. 6), decreased regional mean salinity values both downstream (southwestward) on the ESS, and also to a lesser extent upstream (northeastward) on the WGB (Table 2) are not surprising, with the GSL discharge controlling the overall large-scale mean along-shelf salinity gradient.

An examination of the regional mean NSS values in this study (Fig. 6) depicts a largescale along-shore NSS gradient that is close to zero in the north (computed between NFS and WGB). However, farther south, the along-shore NSS gradient is initially negative: $-1.0 \times 10^{-3}$ $\mathrm{km}^{-1}$, using a distance of $481 \mathrm{~km}$ taken along the outer shelf between WGB and ESS $\left(55^{\circ} \mathrm{W}\right.$ and $60^{\circ} \mathrm{W}$ ), but then becomes positive: $+0.9 \times 10^{-3} \mathrm{~km}^{-1}$, computed between ESS and DHS, using a distance of $1346 \mathrm{~km}$ taken along the outer shelf and through the Gulf of Maine between ESS and DHS $\left(60^{\circ} \mathrm{W}\right.$ and $\left.74^{\circ} \mathrm{W}\right)$. The large-scale positive along-shelf NSS gradient of $+0.9 \times 10^{-3} \mathrm{~km}^{-1}$, computed herein between ESS and DHS is in close agreement with the mean depth-averaged along-shelf salinity gradient computed along the mid-shelf within the Middle Atlantic Bight $\left(+1.0 \times 10^{-3} \mathrm{~km}^{-1}\right)$ reported by Lentz (2010). Moreover, mean precipitation and evaporation rates nearly balance within the region and are thus too small to account for the increase in salinity, requiring an onshore eddy salt flux rather than the cross-shelf salt flux divergence which is of the 
wrong sign (Lentz, 2010). Utilizing the along-shelf "flux variation" model of Sundby and Drinkwater (2007), we can compute a crude estimate of the magnitude of modeled salinity anomalies across the ESS to DHS group of sub-regions using:

$$
\Delta S=\frac{\partial S}{\partial x} \Delta x
$$

where: $\Delta S$ is the calculated salinity residual, $\partial S / \partial x$ is the large-scale along-shelf salinity gradient, and $\Delta x$ is the distance traveled corresponding to an annual-mean velocity anomaly integrated over a one year period.

Computation of the product of $\Delta x$, i.e., the integrated (annual mean) along-shelf current velocity anomalies from $\mathrm{Li}$ et al. (2014) measured at section S1, with $\partial S / \partial x$, the large-scale salinity gradients noted above, results in calculated NSS residuals for the region of negative (positive) salinity gradient computed between WGB and ESS (ESS and DHS) sub-regions (Fig. 20). Results show some similarities between the calculated and observed NSS residuals for the 1993-2008 time period analyzed by Li et al. (2014), with much better agreement for the southern DHS sub-region $(r=0.6312, \mathrm{p} \leq 0.0087$ ) than for the northern ESS sub-region $(\mathrm{r}=-0.1677, \mathrm{p} \leq$ 0.5348). Note that these cross-correlations are identical (except for the sign for ESS) to the crosscorrelations computed between the annual mean along-shelf current velocity anomalies and observed NSS residuals (Table 4), as $\Delta x$ is proportional to velocity. Overall, calculated NSS values are generally within a factor of two of the observed values for DHS for most of the 16 years of comparison when along-shelf velocity anomalies are available (Fig. 20). Despite the relatively crude calculation, the good level of agreement between the observed and calculated $(\Delta S)$ NSS residual magnitudes for the DHS sub-region is surprising given the use of the largescale, climatological along-shelf salinity gradient with annual mean velocity anomalies observed at section S1 located within WSS at the "upstream" end of the analysis region. This level of agreement suggests that "flux variation" within the along-shelf, large-scale NSS gradient as suggested by Sundby and Drinkwater (2007) may be the cause of the large-scale, regional shelfwide salinity changes or "regime shifts" noted by workers along the Canadian and U.S. shelves. Furthermore, significant cross-correlations between annual mean NSS residuals, SBF position anomalies, and along-shelf velocity anomalies (Figs. 12-14; Tables 3 and 4) for the more southern sub-regions strongly suggests that the inter-annual, westward-propagating SBF anomalies of $1-2 \mathrm{~cm} \mathrm{~s}^{-1}$ may also be related to the along-shelf velocity anomalies of similar magnitude noted above along satellite altimeter section S1. Lastly, changing cross-correlation values (Table 3) between the clearly westward-propagating SBF position anomalies (Fig. 12) and the observed simultaneous (in-phase, non-propagating) behavior of NSS residuals over nearly the entire study domain (Fig. 9) are not unexpected. 


\subsection{Summary and Conclusions}

A 41-year analysis (1973-2013) of near-surface salinity (NSS) using two hydrographic datasets (Bedford Institute of Oceanography "Climate”, NOAA/ESDIM, and Canadian Marine Environmental Data Service (MEDS)) allowed an examination of NSS variability within 11 continental shelf sub-regions, extending over $2000 \mathrm{~km}$ from the Newfoundland Shelf of eastern Canada to the DelMarVa/Hatteras Shelf of the United States.

1) The regional mean NSS pattern displays the effects of freshwater inputs from northern sources, e.g., the Labrador Current and melting of sea ice, supplying freshwater to the eastern Newfoundland Shelf, along with the largest single river input of freshwater discharge from the St. Lawrence River (RIVSUM) to the Gulf of St. Lawrence and Scotian Shelf, and other smaller inputs of freshwater to the Gulf of Maine, Middle Atlantic Bight and DelMarVa/Hatteras Shelf. Given these sources of freshwater, the large range of mean NSS ( $>2.0)$ over the study domain is expected and in agreement with previous studies of broad-scale shelf NSS patterns and inputs from freshwater sources (Loder et al. 1998), displaying a similar range across all sub-regions during both winter and summer. The overall pattern displays a strong salinity minimum corresponding to the Gulf of St. Lawrence and the adjacent Eastern Scotian Shelf due to outflowing low-salinity waters through Cabot Strait, with higher salinities located upstream (downstream) towards the Newfoundland Shelf (DelMarVa/Hatteras Shelf). The large-scale, along-shelf salinity gradient computed between the Eastern Scotian Shelf and Western Grand Banks (Eastern Scotian Shelf and DelMarVa/Hatteras Shelf) is $-1.0 \times 10^{-3} \mathrm{~km}^{-1}\left(+0.9 \times 10^{-3} \mathrm{~km}^{-}\right.$ ${ }^{1}$ ) and therefore are of opposite signs but of nearly equal magnitudes.

2) Long-term (1973-2013) mean annual variations of NSS show a prevalence of late spring to summer minima associated with each river's spring freshet for more southern sub-regions as far north as the Western Scotian Shelf in agreement with Loder et al. (1998). Further north, from the Eastern Scotian Shelf to the Eastern Newfoundland Shelf, NSS minima are associated with late summer and fall periods when freshwater from sea ice melt and RIVSUM discharge travels downriver, and maximum southward Labrador Current transport occurs, with a later phase located further downstream in accordance with southwestward propagation of annual salinity minima. Furthermore, the long-term (1973-2013) mean annual SBF position also displays an annual westward-propagating offshore SBF position, entering the eastern end of the domain at $50^{\circ} \mathrm{W}$ during November of each year. This feature moves steadily westward at $3.2 \mathrm{~km} \mathrm{~d}^{-1}(\sim 0.04$ $\mathrm{m} \mathrm{s}^{-1}$ ) to $57^{\circ} \mathrm{W}$ by April, with the timing of this late fall feature likely related to a shelf water volume maximum resulting from the annual transport maximum of the Labrador Current during September-October of each year. This conclusion is also supported by the annual NSS minimum, shown to occur between late August to early October for the Newfoundland Shelf and propagating to the Western Grand Banks by late fall. This relationship provides strong evidence that the SBF may be responding seasonally to the annual increase in transport of lower-salinity Labrador Current water from the Labrador Sea.

3) Long-term (1973-2013) trends of annual mean NSS on the Canadian and U.S. shelves, despite data limitations, show some regional agreement along with trend reversals across the 11 sub-regions examined herein. On the Newfoundland Shelf, the linear NSS trend is significant and positive, but there are few data prior to 1992 that are able to adequately describe annual mean NSS between 1973 and 1992. Data are also sparse for the Grand Banks, with no apparent trend for the Eastern Grand Banks and Tail of the Grand Banks sub-regions. The apparent 
increase in NSS for the Western Grand Banks through 2007 and decreasing thereafter is similar to that for the Eastern Scotian Shelf where salinity increased through 1992, but then decreased thereafter. Further west, the Western Scotian Shelf, Gulf of Maine, and Georges Bank subregions show significant, long-term linear trends of decreasing salinity of $\mathrm{O}(-0.1$ per decade), with very few missing data points over the 41-year (1973-2013) period of record. Further downstream, the Middle Atlantic Bight and DelMarVa/Hatteras Shelf sub-regions display no significant trend and a strongly positive linear trend, respectively, thus transitioning to a region where changes in the sub-tropical gyre and Gulf Stream may be dominant. The Gulf of St. Lawrence displays no long-term trend of NSS and is therefore not in agreement with the longterm trend of annual mean RIVSUM discharge values that shows a significant negative trend for the 41-year (1973-2013) period of record. Speculating here, increased transport within the inshore branch of the Labrador Current may be responsible for the "missing" freshwater transport into the Gulf of St. Lawrence.

4) Inter-annual variability of annual mean NSS residuals displays two distinct zones of high cross-correlation: one located northeast of Laurentian Channel where the mse of NSS residuals vary between approximately 0.03-0.04, and the second located southwest of Laurentian Channel where mse of NSS residuals are much larger (0.10-0.30). Moreover, inter-annual variability of NSS residuals appears to be coherent at 0-year lag within each of the two zones, exhibiting significant positive cross-correlation values across each zone. The strong coherence between inter-annual variability of the annual mean NSS residuals is compelling as evidenced by their significant positive cross-correlations at 0-year lag for sub-regions contained within each of the northern and southern zones. The along-shelf scale of such correspondence is clearly of a broadscale nature, i.e., regional, given the overall size (approx. $2000 \mathrm{~km}$ ) of the combined Canadian and U.S. shelf and the well-known advective and linked nature of their circulation. More specifically, NSS residuals are clearly in phase between the Eastern Scotian Shelf and the southern-most DelMarVa/Hatteras Shelf, over a distance of approximately $1400 \mathrm{~km}\left(60^{\circ} \mathrm{W}\right.$ to $75^{\circ} \mathrm{W}$ ), with mse of the NSS residuals increasing by at least a factor of four over this distance. While the along-shelf "patch advection" model of Sundby and Drinkwater (2007) for NSS residuals observed in this study cannot absolutely be disproven, salinity anomalies within the "upstream" Labrador Sea have been shown to propagate at speeds that are generally too small by a factor of 2-3. Consideration of Sundby and Drinkwater's "flux variation" model, that in this case includes along-shelf, altimeter-derived velocity anomalies computed upstream on the Western Scotian Shelf and the positive along-shelf mean salinity gradient between the Eastern Scotian Shelf and the DelMarVa/Hatteras Shelf, results in calculated NSS residuals that are within a factor of two of observed NSS residuals for the DelMarVa/Hatteras Shelf. Furthermore, co-varying broad-scale coastal sea level and shelf break front position anomalies also support the flux variation model, along with CMV Oleander temperature anomalies across a limited Middle Atlantic Bight shelf region. Overall, the relationships between along-shelf observations of NSS and other shelf parameters described above strongly support the along-shelf wind-driven model of Li et al. (2014), describe inter-annual variability along the entire Canadian and U.S shelf for periods greater that one year, and may provide useful indices of "regime change" within the overall Northeast Shelf Large Marine Ecosystem.

5) The effects of a decreasing NSS trend on long-term changes in the physical, chemical, and biological characteristics for the highly productive Gulf of Maine sub-region, one of the most thoroughly sampled sub-regions for this study, may be large, given the dominance of 
salinity on stratification of surface waters within the Gulf of Maine from October-April, especially within the eastern portion of the Gulf (Li et al., 2015). As noted by Deese-Riordan (2009), a decrease of 1 PSU for Jordan Basin salinity within the Gulf of Maine is equivalent to the density change caused by $10-12{ }^{\circ} \mathrm{C}\left(1-2^{\circ} \mathrm{C}\right)$ of warming during winter (summer). Given these proportionalities, the noted change of approximately -0.4 for NSS over the 41 years of this study has resulted in a density decrease equivalent to a warming of $4-6{ }^{\circ} \mathrm{C}\left(0.4-0.8{ }^{\circ} \mathrm{C}\right)$ during winter (summer). Such long-term changes, when coupled with recently noted inter-annual variability of salinity, driven largely by annual differences in freshwater discharge by rivers into the Gulf of Maine, may lead to continued variability in density stratification, nutrient and chlorophyll concentrations, and carbon fixation within Gulf of Maine surface waters as noted by Balch et al. (2012). Additional work using new hydrographic data from continued monitoring efforts for the entire Northeast Shelf Large Marine Ecosystem within both Canadian and U.S. waters is underway at this time. 


\section{Acknowledgements}

This work was supported by the National Science Foundation through grant OCE-0227679 under the US-GLOBEC NW Atlantic Georges Bank Program, along with NOAA/ESDIM funding. This work was also supported in part through my recent sabbatical from the University of Massachusetts, Dartmouth, hosted by G. Gawarkiewicz at the Woods Hole Oceanographic Institution (WHOI), Woods Hole, Massachusetts. The following WHOI colleagues provided data and/or useful discussions for this work: M. Andres, K. Brink, C. Cenedese, J. Forsyth, G. Gawarkiewicz, S. Lentz, Y. Li, and R. Todd. Special thanks to K. Drinkwater, Institute for Marine Research, Bergen, Norway, and R. Pettipas, Bedford Institute of Oceanography, Dartmouth, Nova Scotia, for providing shelf break front positional data and D. Mountain, University of Arizona, Tucson, Arizona, for providing additional hydrographic data through the NOAA/ESDIM program. 


\section{REFERENCES}

Andres, M., G. G. Gawarkiewicz, and J. M. Toole, 2013. Interannual sea level variability in the western North Atlantic: Regional forcing and remote response, Geophys. Res. Lett., 40, 5915-5919, doi:10.1002/2013GL058013.

Balch W. M., D. T. Drapeau, B. C. Bowler, T. G. Huntington. 2012. Step-changes in the physical, chemical and biological characteristics of the Gulf of Maine, as documented by the GNATS time series. Mar. Ecol. Progr. Ser., 450:11-35.

Beardsley, R.C., and C. N. Flagg, 1976. The water structure, mean currents, and shelf water/slope water front of the New England continental shelf. Mem. Soc. Roy. Sci. Liege, 10:209-225.

Belkin, I. M., S. Levitus, J. I. Antonov, and S.-A. Malmberg, 1998. "Great Salinity Anomalies” 'in the North Atlantic. Prog. In Oceanogr. 41:1-68.

Belkin, I. M., 2004. Propagation of the "Great Salinity Anomaly" of the 1990s around the northern North Atlantic. Geophysical Research Letters, 31, L08306, doi:10.1029/2003GL019334.

Bigelow, H. B., 1927. Physical oceanography of the Gulf of Maine. Bull. U.S. Fish. Bur., 40:511-1027.

Bigelow, H. B., and M. Sears, 1935. Studies of the waters on the continental shelf, Cape Cod to Chesapeake Bay, II, Salinity, Pap. Phys. Oceanogr. Meteorol., 4, 1-94.

Bisagni, J. J., 1992. Differences in the annual stratification cycle over short spatial scales on southern Georges Bank. Cont. Shelf Res., 12:415-435.

Bisagni, J. J., H.-S. Kim, and K. F. Drinkwater, 2006. Observations and modeling of shelf-slope front seasonal variability between $75^{\circ}$ and $50^{\circ} \mathrm{W}$. Deep-Sea Research II, 53:2477-2500.

Bisagni, J. J., H-S. Kim, and A. Chaudhuri, 2009. Inter-annual variability of the shelf slope front position between $75^{\circ}$ and $50^{\circ}$ W. Journal of Marine Systems, 78:337-350.

Buckley, L. J., and E. G. Durbin. 2006. Seasonal and inter-annual trends in the zooplankton prey and growth rate of Atlantic cod (Gadus morhua) and haddock (Melanogrammus aeglefinus) larvae on Georges Bank. Deep-Sea Res. II 53: 2758-2770.

Chapman, D. C., J. A. Barth, R. C. Beardsley, and R. G. Fairbanks, 1986. On the continuity of mean flow between the Scotian Shelf and the Middle Atlantic Bight. J. Phys. Oceanogr., 16:758-772.

Chapman, D. C., and R. C. Beardsley, 1989. On the origin of shelf water in the Middle Atlantic Bight. J. Phys. Oceanogr., 19:384-391.

Chen, K., G. G. Gawarkiewicz, S. J. Lentz, and J. M. Bane, 2014. Diagnosing the warming of the Northeastern U.S. Coastal Ocean in 2012: A linkage between the atmospheric jet stream variability and ocean response. J. Geophys. Res., 118, doi:10.1002/2013JC009393.

Chen, K., G. Gawarkiewicz, Y.-O. Kwon, and W. G. Zhang (2015), The role of atmospheric forcing versus ocean advection during the extreme warming of the Northeast U.S. continental shelf in 2012, J. Geophys. Res., 120, doi:10.1002/2014JC010547. 
Deese-Riordan, H. E., 2009. Salinity and stratification in the Gulf of Maine: 2001-2008. Ph.D. Dissertation, University of Maine, 194 pp.

Dickson, R. R., J. Meincke, S.-A. Malmberg, and A. J. Lee, 1988. The "Great Salinity Anomaly" in the northern Atlantic 1968-1982. Prog. In Oceanogr. 20:103-151.

Doubleday, W. G. (ed.), 1981. Manual on groundfish surveys in the Northwest Atlantic. NAFO Sci. Coun. Studies, 2, 55 pp.

Drinkwater, K. F., R. A. Myers, R. G. Pettipas, and T. L. Wright, 1994. Climatic data for the Northwest Atlantic: The position of the shelf/slope front and northern boundary of the Gulf Stream between $50^{\circ}$ and $75^{\circ} \mathrm{W}, 1973-1992$. Canadian Data Report of Hydrography and Ocean Sciences 125, 103 pp. Dept. of Fisheries and Oceans, Dartmouth, Nova Scotia, Canada B2Y 4A2.

Drinkwater, K. F., 1996. Atmospheric and oceanic variability in the northwest Atlantic during the 1980s and early 1990s. J. Northw. Atl. Fish. Sci. 18:77-97

Durbin, E.G., Campbell, R.G., Casas, M.C., Ohman, J.D., Niehoff, B., Runge, J., Wagner, M. 2003. Interannual variation in phytoplankton blooms and zooplankton productivity and abundance in the Gulf of Maine during winter. Mar. Ecol. Prog. Ser. 254:81-100.

Fairbanks, R. G., 1982. The origin of continental shelf and slope water in the New York Bight and Gulf of Maine: Evidence from $\mathrm{H}_{2}{ }^{18} \mathrm{O} / \mathrm{H}_{2}{ }^{16} \mathrm{O}$ ratio measurements. J. Geophys. Res., 87:5796-5808

Flagg, C. N., 1977. The kinematics and dynamics of the New England continental shelf and shelf/slope front. Ph.D. Dissertation, Massachusetts Institute of Technology and Woods Hole Oceanographic Institution, 207 pp.

Flagg, C., G. Schwartze, E. Gottlieb, and T. Rossby, 1998. Operating an acoustic Doppler current profiler (ADCP) aboard a container vessel, J. Atmos. Oceanic Technol., 15, 257271.

Fofonoff, N. P., and H. Bryden. 1975. Specific gravity and density of seawater at atmospheric pressure. J. Mar. Res. 33 (suppl.): 69-82.

Forsyth, J. S. T., M. Andres, and G. G. Gawarkiewicz, 2015. Recent accelerated warming of the continental shelf off New Jersey: Observations from the CMV Oleander expendable bathythermograph line, J. Geophys. Res., 120, doi:10.1002/2014JC010516.

Garvine, R. W., K. C. Wong, G. G. Gawarkiewicz, and R. K. McCarthy, 1988. The morphology of shelfbreak eddies. J. Geophys. Res., 93:15593-15607.

Greenberg, D. A., and B. D. Petrie, 1988. The mean barotropic circulation on the Newfoundland shelf and slope. J. Geophys. Res., 93:15541-15550.

Gregory, D.N., 2004. Climate: A database of temperature and salinity observations for the northwest Atlantic. DFO Can. Sci. Advis. Sec. Res. Doc. 2004/075. 10 p.

Hakkinen, S., and P. B. Rhines, 2004. Decline of subpolar North Atlantic circulation during the 1990s, Science, 304, 555-559. 
Halliwell, G. R., and C. N. K. Mooers, 1979. The space-time structure and variability of the shelf-water-slope water and Gulf Stream surface temperature fronts and associated warmcore eddies. J. Geophys. Res., 84:7707-7725.

Han, G., and C. L. Tang, 2001. Interannual variations of volume transport in the western Labrador Sea based on TOPEX/Poseidon and WOCE data, J. Phys. Oceanogr., 31, 199211.

Han, G., N. Chen, and Z. Ma, 2014. Is there a north-south phase shift in the surface Labrador Current on the interannual-to-decadal scale?, J. Geophys. Res., 119, 276-287, doi:10.1002/2013JC009102.

Han, G., K. Ohashi, N. Chen, P. G. Myers, N. Nunes, and J. Fischer, 2010. Decline and partial rebound of the Labrador Current 1993-2004: Monitoring ocean currents from altimetric and conductivity temperature-depth data, J. Geophys. Res., 115, C12012, doi:10.1029/ 2009JC006091.

Hannah, C. G., J. A. Shore, J. W. Loder, and C. E. Naimie, 2001. Seasonal circulation on the western and central Scotian Shelf. J. Phys. Oceanogr., 31, 591-615.

Head, E. J. H., D. Brickman, and L. R. Harris. 2005. An exceptional haddock year class and unusual environmental conditions on the Scotian Shelf in 1999. J. Plankton Res. 27:597602.

Houghton, R. W. and M. H. Visbeck, 2002. Quasi-decadal salinity fluctuations in the Labrador Sea. J. Phys. Oceanogr., 32:687-701.

Khatiwala, S.P., R. G. Fairbanks, and R. W. Houghton, 1999. Freshwater sources to the coastal ocean off northeastern North America: Evidence from $\mathrm{H}_{2}{ }^{18} \mathrm{O} / \mathrm{H}_{2}{ }^{16} \mathrm{O}$. J. Geophys. Res., 104: doi: 10.1029/1999JC900155. issn: 0148-0227.

Koutitonsky, V. G., Wilson, R. E., and El-Sabh, M. I. (1990) On the seasonal response of the lower St. Lawrence estuary to buoyancy forcing by regulated river runoff. Estuarine, Coastal and Shelf Science, 31 359-379.

Lazier, J. R. N., and D. G. Wright, 1993. Annual velocity variations in the Labrador Current. J. Phys. Oceanogr., 23:659-678.

Lentz, S. J., 2008. Observations and a model of the mean circulation over the Middle Atlantic Bight. J. Phys. Oceanogr., 38:1203-1221.

Lentz, S. J., 2010. The mean along-isobath heat and salt balances over the Middle Atlantic Bight continental shelf. J. Phys. Oceanogr., 40:934-948.

Li, Y., R. Ji, P. S. Fratantoni, C. Chen, J. A. Hare, C. S. Davis, and R. C. Beardsley, 2014. Windinduced interannual variability of sea level slope, alongshelf flow, and surface salinity on the Northwest Atlantic shelf, J. Geophys. Res. Oceans, 119, 2462-2479, doi:10.1002/2013JC009385.

Li., Y., P. S. Fratantoni, C-S. Chen, J. A. Hare, Y. Sun, R. C. Beardsley, and R. Ji, 2015. Spatiotemporal patterns of stratification on the Northwest Atlantic shelf. Prog. In Oceanogr., 134: 123-137 
Linder, C. A., and G. Gawarkiewicz, 1998. A climatology of the shelfbreak front in the Middle Atlantic Bight. J. Geophys. Res., 103:18405-18423.

Linder, C. A., G. G. Gawarkiewicz, and M. Taylor, 2006. Climatological estimation of environmental uncertainty over the Middle Atlantic Bight shelf and slope, IEEE J. Oceanic Engin. (Special Issue on Capturing Uncertainty), 31(2):308-324

Loder, J. W., B. D. Petrie, and G. Gawarkiewicz, 1998. The coastal ocean off northeastern North America: A large-scale view. In: Brink, K. H. and A. R. Robinson (Eds.), The Global Coastal Ocean: Regional Studies and Synthesis. The Sea, v. 11, Wiley, New York, pp. 105133 (Chapter 5).

Loder, J. W., J. A. Shore, C. G. Hannah, B. D. Petrie, 2001. Decadal-scale hydrographic and circulation variability in the Scotia-Maine region. Deep-Sea Res. II, 48: 3-35.

Mountain, D. G., and J. P. Manning, 1994. Seasonal and interannual variability in the properties of the surface waters of the Gulf of Maine, Cont. Shelf Res., 14, 1555-1581

Mountain, D. G., and M. H. Taylor, 1998. Spatial coherence of interannual variability in water properties on the U.S. northeast shelf, J. Geophys. Res., 103, 3083-3092

Mountain, D. G., 2003. Variability in the properties of Shelf Water in the Middle Atlantic Bight, 1977-1999. J. Geophys. Res., 108, 3014, doi:10.1029/2001JC001044.

Mountain, D, G. and J. Kane, 2010 Major changes in the Georges Bank ecosystem, 1980s to 1990s. Mar. Ecol. Prog. Ser. 398:81-91.

Myers, R. A., S. A. Akenhead, and K. Drinkwater, 1990. The influence of Hudson Bay runoff and ice-melt on the salinity of the inner Newfoundland shelf. Atmos. -Ocean 28:241-256.

Ohashi, K. and J. Sheng, 2013. Influence of St. Lawrence River discharge on the circulation and hydrography in Canadian Atlantic waters. Cont. Shelf Res., 58:32-49.

Pershing, A. J., Greene, C. H., Jossi, J. W., O’Brien, L., Brodziak, J. K. T., and Bailey, B. A. 2005. Inter-decadal variability in the Gulf of Maine zooplankton community, with potential impacts on fish recruitment. ICES Journal of Marine Science, 62: 1511e1523.

Peterson, I., 1987. A snapshot of the Labrador Current inferred from ice-flow movement in NOAA satellite imagery. Atmos. -Ocean., 25:402-415.

Petrie, B. D., 2007. Does the north Atlantic oscillation affect hydrographic properties on the Canadian Atlantic continental shelf?, Atmos. -Ocean 45:3, 141-151, doi: 10.3137/ao.450302

Petrie, B. D., and C. Anderson, 1983. Circulation of the Newfoundland continental shelf. Atmos. -Ocean., 21:207-226.

Platt, T., Fuentes-Yaco, C., Frank, K.T. 2003. Spring algal bloom and larval fish survival. Nature (London). 423:398-399.

Rossby, T., C. Flagg, and K. Donohue, 2010. On the variability of Gulf Stream transport from seasonal to decadal timescales, J. Mar. Res., 68:503-522.

Smith, E. H., F. M. Soule, and O. Mosby, 1937. The Marion and General Green expeditions to Davis Strait and Labrador Sea. Bull. Of the U.S. Coast Guard, 19, 259 pp.

Smith, P. C., 1989. Seasonal and interannual variability of current, temperature and salinity off southwest Nova Scotia. Canadian Journal of Fisheries and Aquatic Sciences, 46, Supplement No. 1, 4-20. 
Smith, P. C., R. W. Houghton, R. G. Fairbanks, and D. G. Mountain, 2001. Interannual variability of boundary fluxes and water mass properties in the Gulf of Maine and on Georges Bank: 1993-1997. Deep-Sea Res. II, 48:37-70

Smith, P.C., Pettigrew, N.R., Yeats, P., Townsend, D., Han, G., 2012. Regime shift in the Gulf of Maine. Transactions of the American Fisheries Society. In: Proceedings of the Scientific Symposium on the Gulf of Maine, St. Andrews, NB, October 2009.

Song, H., Ji., R., Stock, C., Wang, Z. 2010. Phenology of phytoplankton blooms in the Nova Scotia Shelf-Gulf of Maine region: remote sensing and modeling analysis. J. Plankton Res. 32:1485-1499.

Sundby, S. and K. Drinkwater, 2007. On the mechanisms behind salinity anomaly signals of the northern North Atlantic. Prog. In Oceanogr., 73: 190-202

Sutcliffe, W. H., Jr., R. H. Loucks, and K. F. Drinkwater, 1976. Coastal circulation and physical oceanography of the Scotian Shelf and the Gulf of Maine. J. Fish. Res. Bd. Can., 33:98-115.

Worst, J. S., K.A. Donohue, and T. Rossby, 2014. A comparison of vessel-mounted acoustic Doppler current profiler and satellite altimeter estimates of sea surface height and transports between New Jersey and Bermuda along the CMV Oleander route, J. Atmos. Oceanic Technol., 31, 1422-1433, doi:10.1175/JTECH-D-13-00122.1

Wright, R. W. and C. E. Parker, 1976. A volumetric temperature/salinity census for the Middle Atlantic Bight. Limnol. Oceanogr., 21:563-571. 


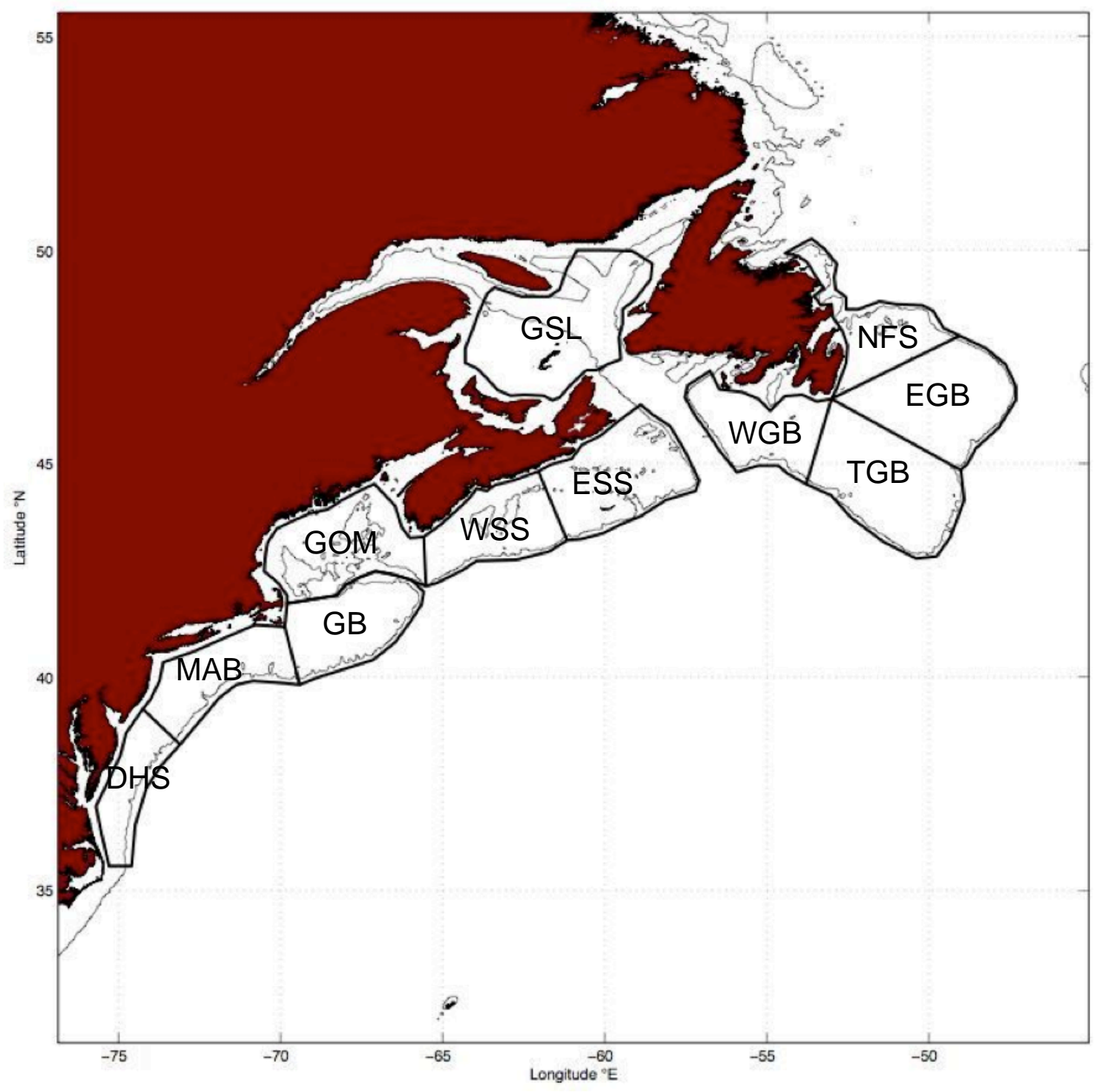

Figure 1. The continental shelf region located offshore of eastern Canada and the northeastern United States (200-m isobath is shown) along with the locations of the 11 sub-regions used for partitioning the near-surface salinity (NSS) data for this study. The sub-regions include: Newfoundland Shelf (NFS), Eastern Grand Banks (EGB), Tail of the Grand Banks (TGB), Western Grand Banks (WGB), Gulf of St. Lawrence (GSL), Eastern Scotian Shelf (ESS), Western Scotian Shelf (WSS), Gulf of Maine (GOM), Georges Bank (GB), Middle Atlantic Bight (MAB), and DelMarVa/Hatteras Shelf (DHS). 

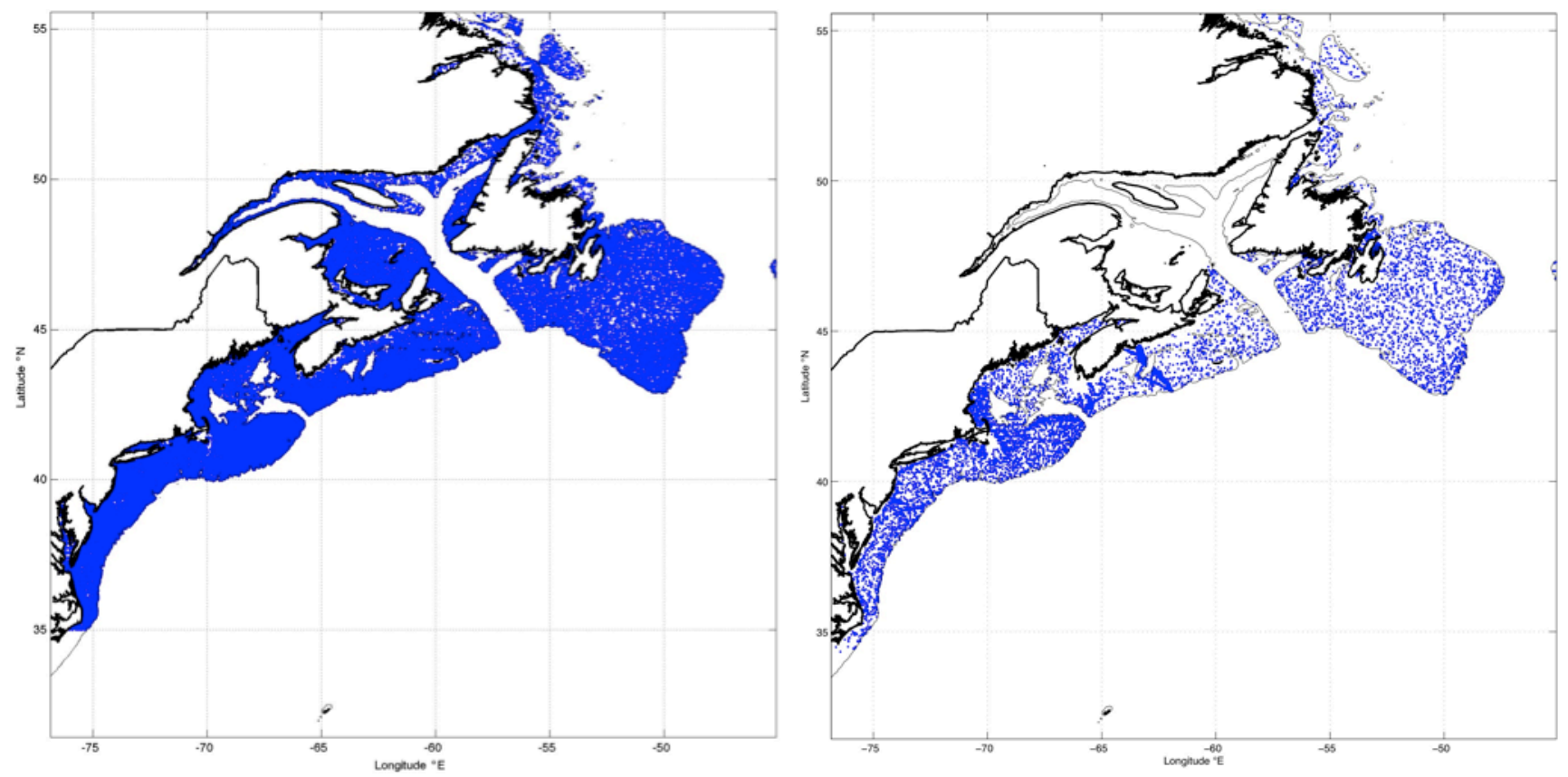

Figure 2. Left panel: All BIO + ESDIM hydrographic climate continental shelf database stations, 1973 through January 2010. Right panel: All MEDS continental shelf database stations, February 2010 through December 2013. (200-m isobath is shown) 


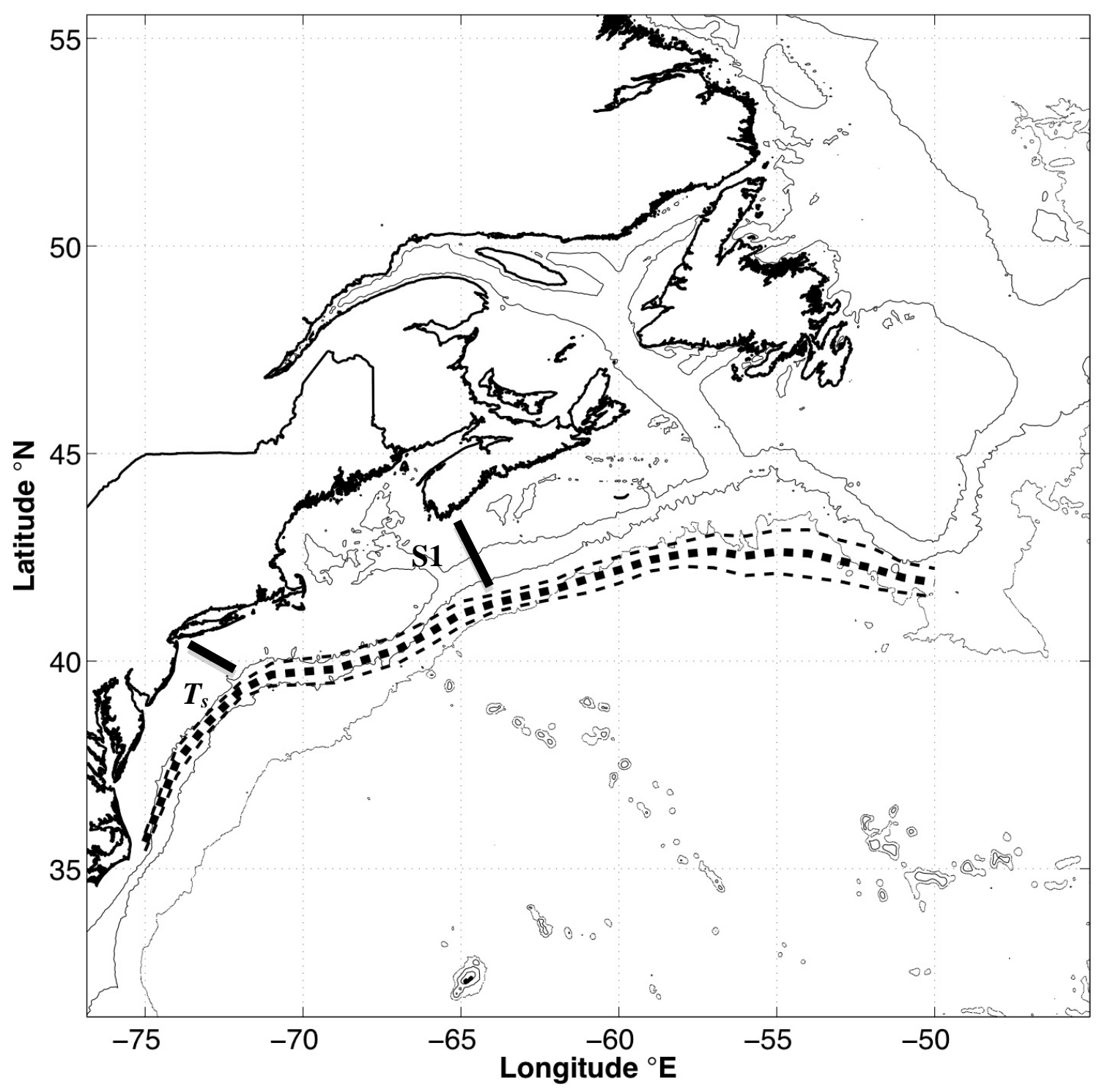

Figure 3. Global mean position of the surface SBF (heavy dashed line) \pm 2 standard deviations (light dashed lines) along 26 lines of longitude $\left(50^{\circ}-75^{\circ} \mathrm{W}\right)$ derived from a 41-year (1973-2013) analysis of monthly-mean satellite-derived SST data. Also shown are the 200-m, 2500-m and $4000-\mathrm{m}$ isobaths and the nominal locations of satellite altimeter section $\mathrm{S} 1$ and the $C M V$ Oleander temperature transect section $T_{s}$ (heavy black lines). 


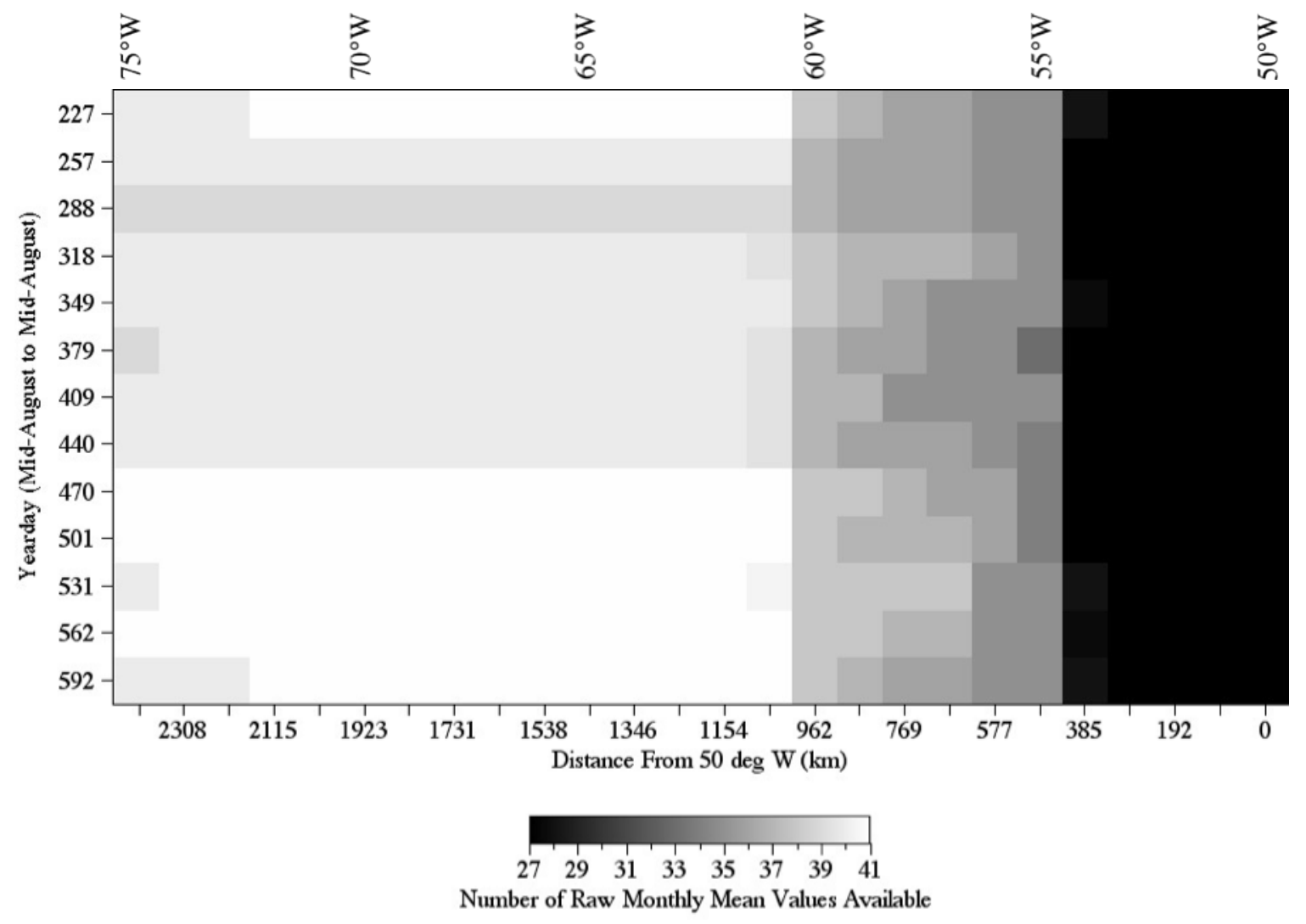

Figure 4. Number of raw BIO monthly mean SBF values used to compute the long-term, 41-year (1973-2013) monthly-mean annual cycle and inter-annual variability (IAV) of SBF positional anomalies along 26 longitude lines between $50^{\circ}$ and $75^{\circ} \mathrm{W}$. 


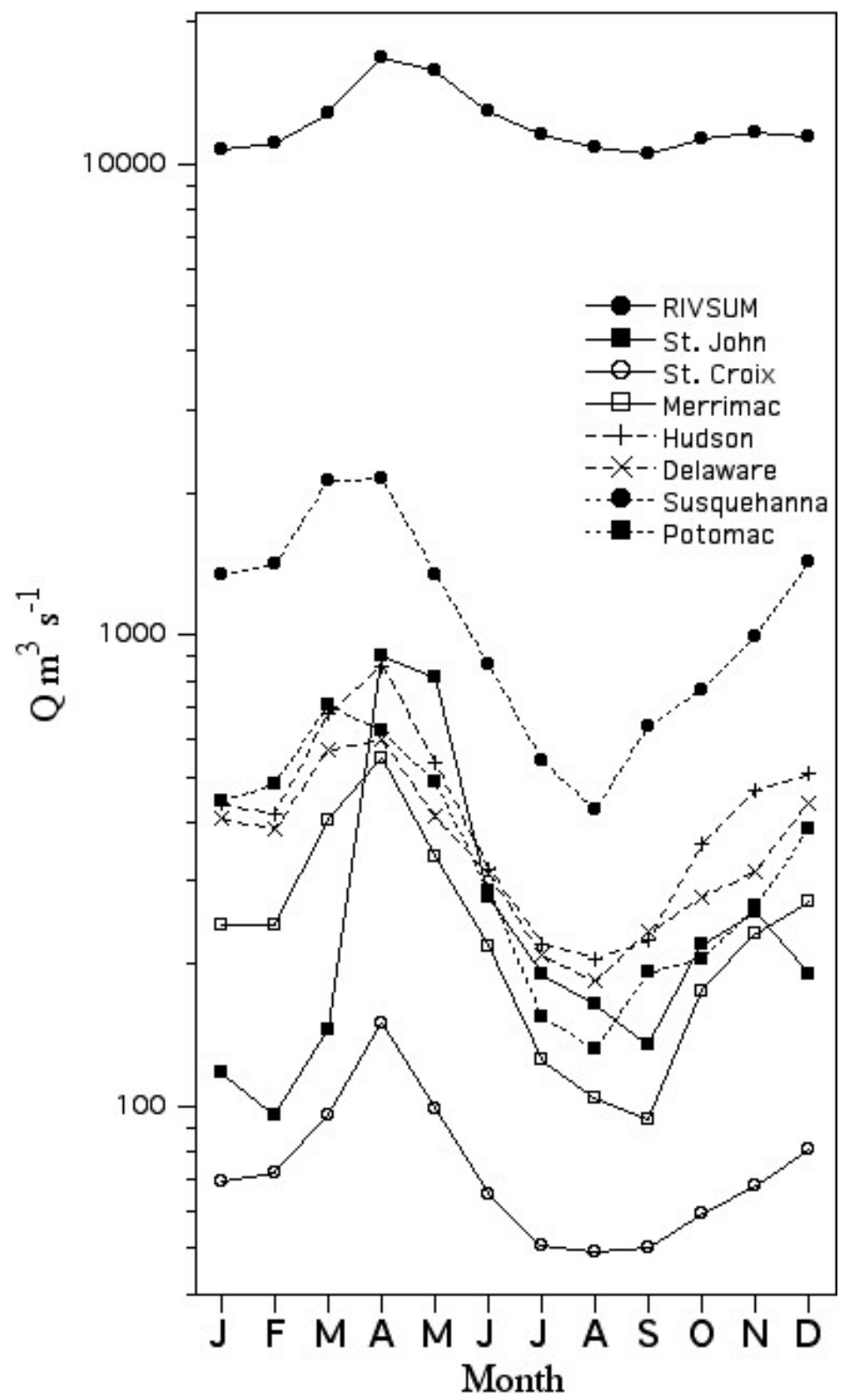

Figure 5. Annual cycle of long-term monthly mean river discharge (Q) for 8 rivers for the 41year (1973-2013) period, corresponding to 7 of the southern-most sub-regions (GSL and south) shown in Fig. 1. 


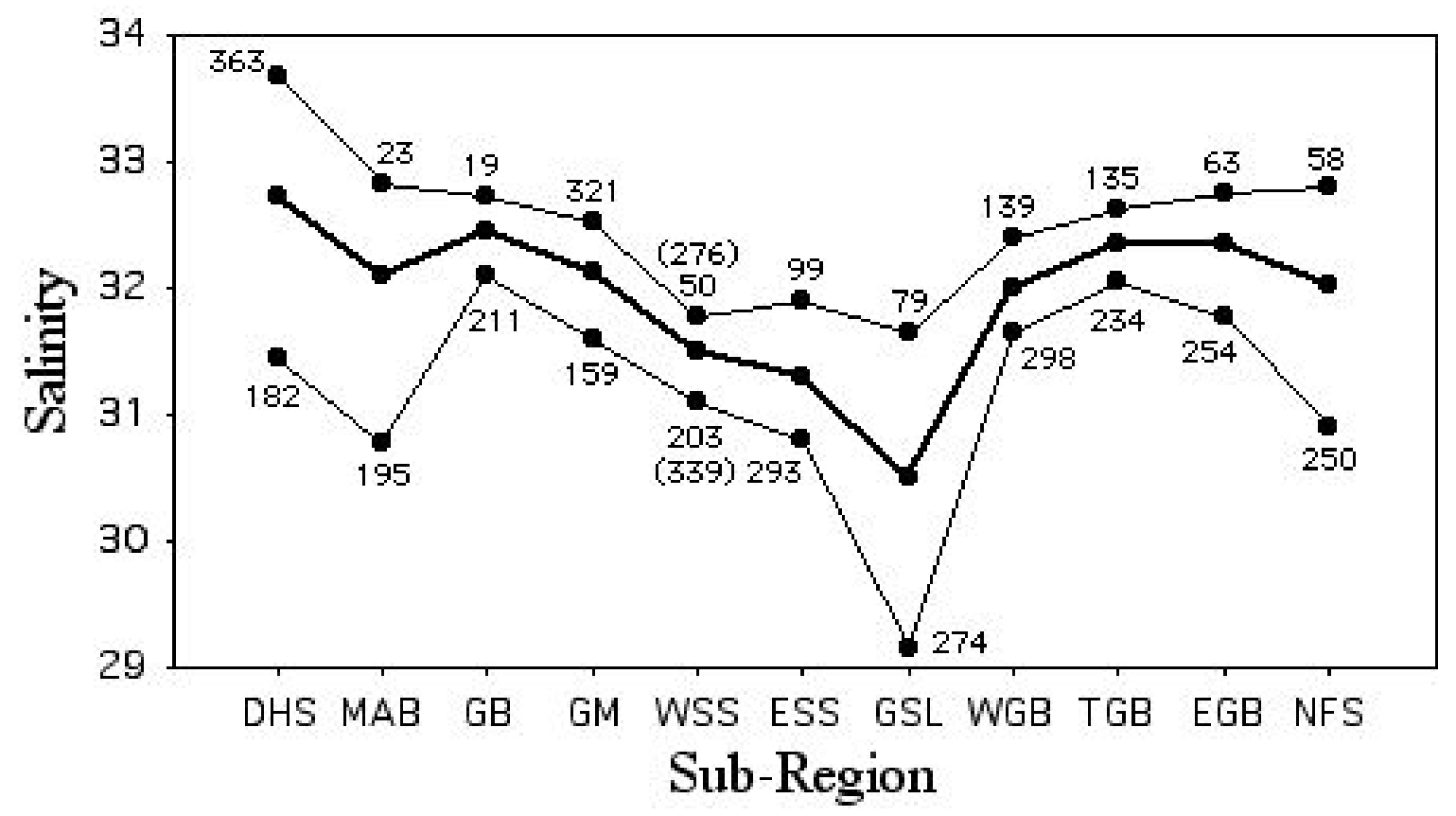

Figure 6. Global mean NSS for each sub-region (heavy line), along with the minimum and maximum NSS for each sub-region's annual cycle. Also shown is the year-day of occurrence for each extremum. Values in (parentheses) indicate the year-day of occurrence of a secondary minimum and maximum for the WSS sub-region. 


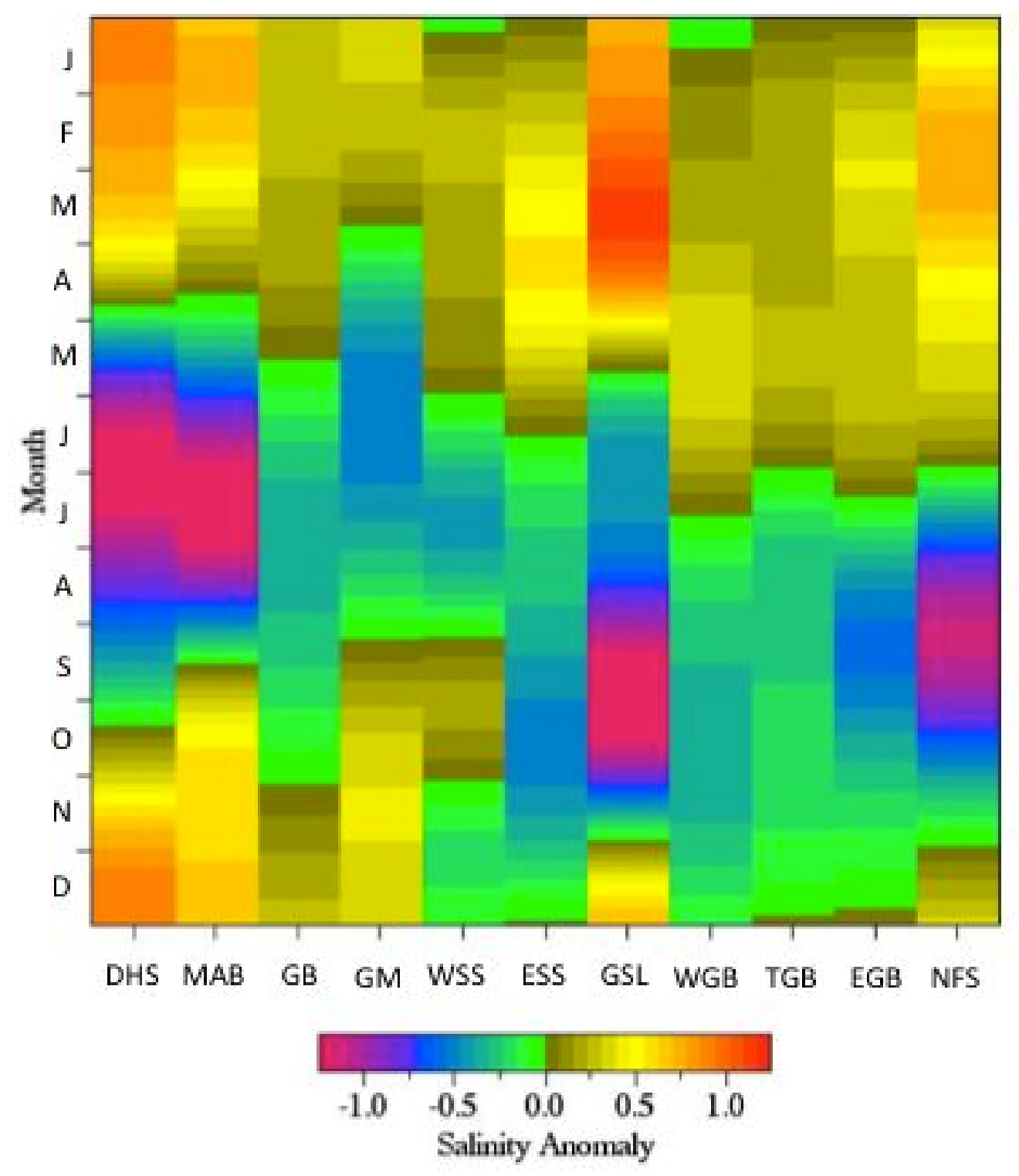

Figure 7. Annual cycle of NSS anomalies for each sub-region relative to the global mean NSS values given in Figure 7. Note the apparent propagation of NSS anomaly minima and maxima (from east-to-west) from the NFS to the WGB, from the GSL to the WSS, and the dual minima and maxima for the WSS sub-region. 

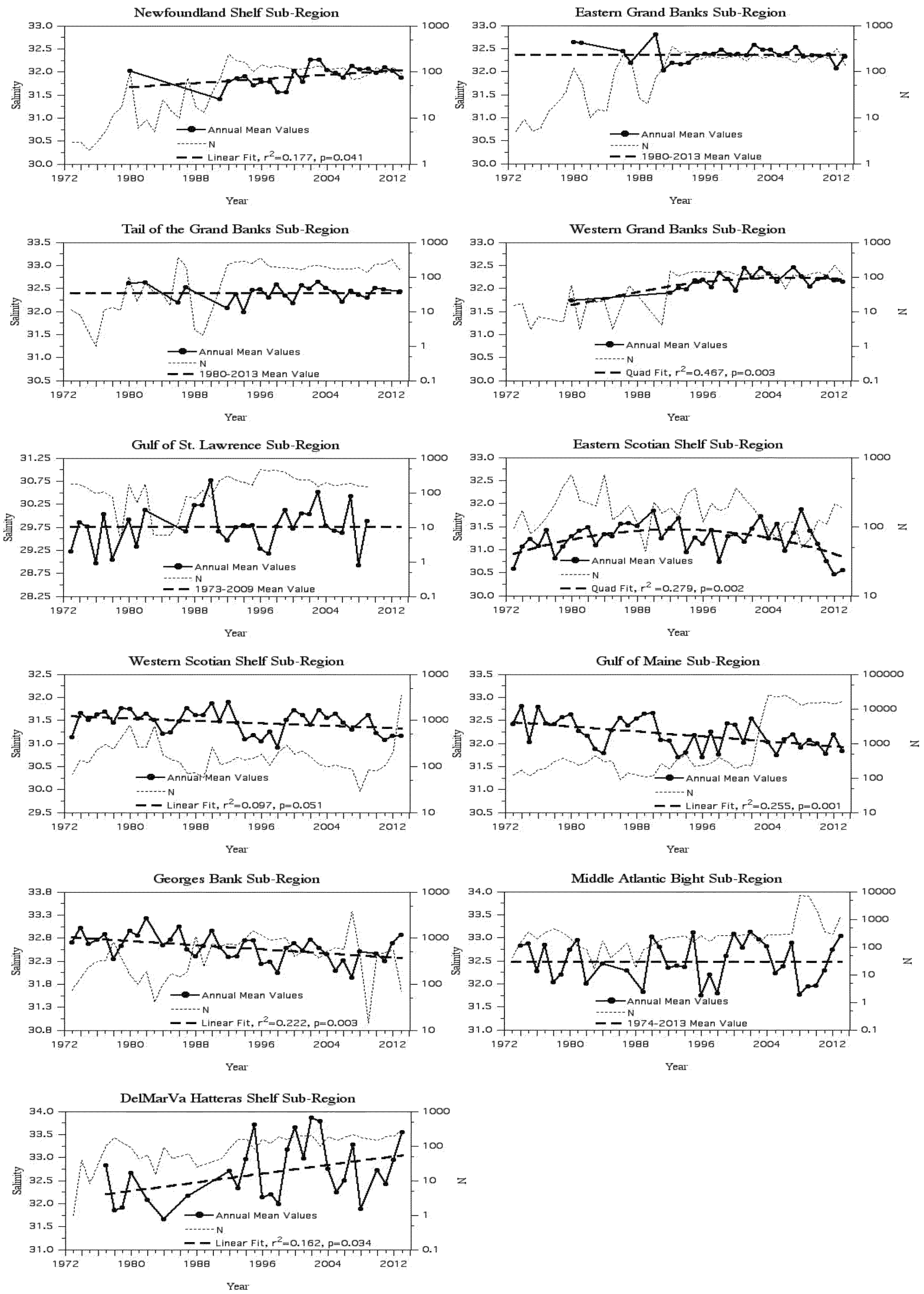

Figure 8. Annual mean NSS for the 11 sub-regions given in Figure 1 and number of observations for each year (N) over the 1973-2013 study period. Fitted NSS model trend statistics (linear or quadratic) are shown if significant, otherwise an overall mean NSS is displayed. Missing years signify insufficient data available. 


\section{All Sub-Regions}

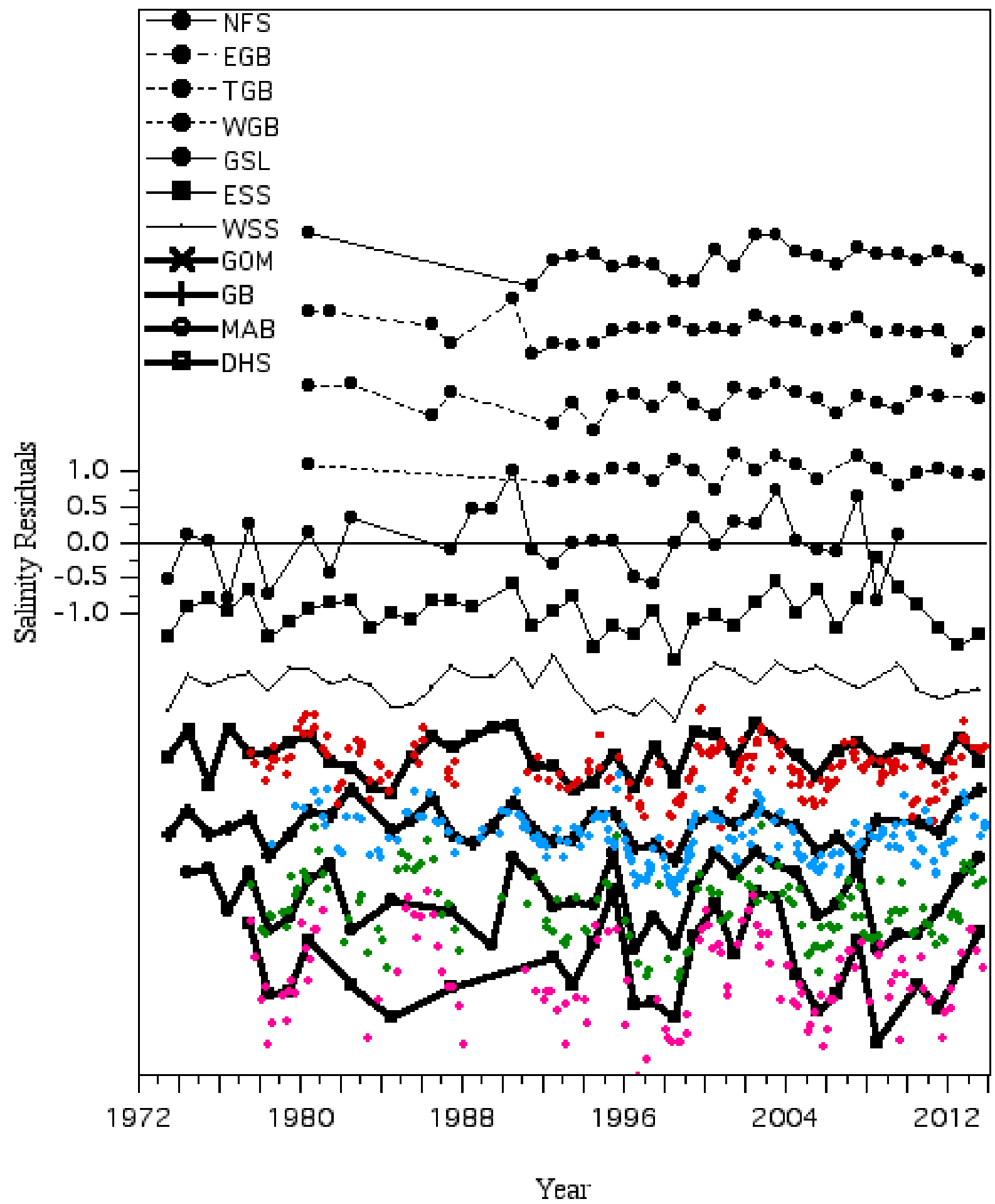

Figure 9. Annual mean NSS residuals for all 11 sub-regions given in Figure 1 over the 19732013 study period. Individual time series plots are arranged from north-to-south, with successive plots offset by 1 PSU. Missing years signify insufficient data. The four southern-most sub-region plots, GOM, GB, MAB and DHS (bold lines) are shown along with the corresponding surface salinity anomalies computed for each NOAA/NMFS survey cruise (colored dots) relative to the MARMAP base period, 1977-1987. 
a)
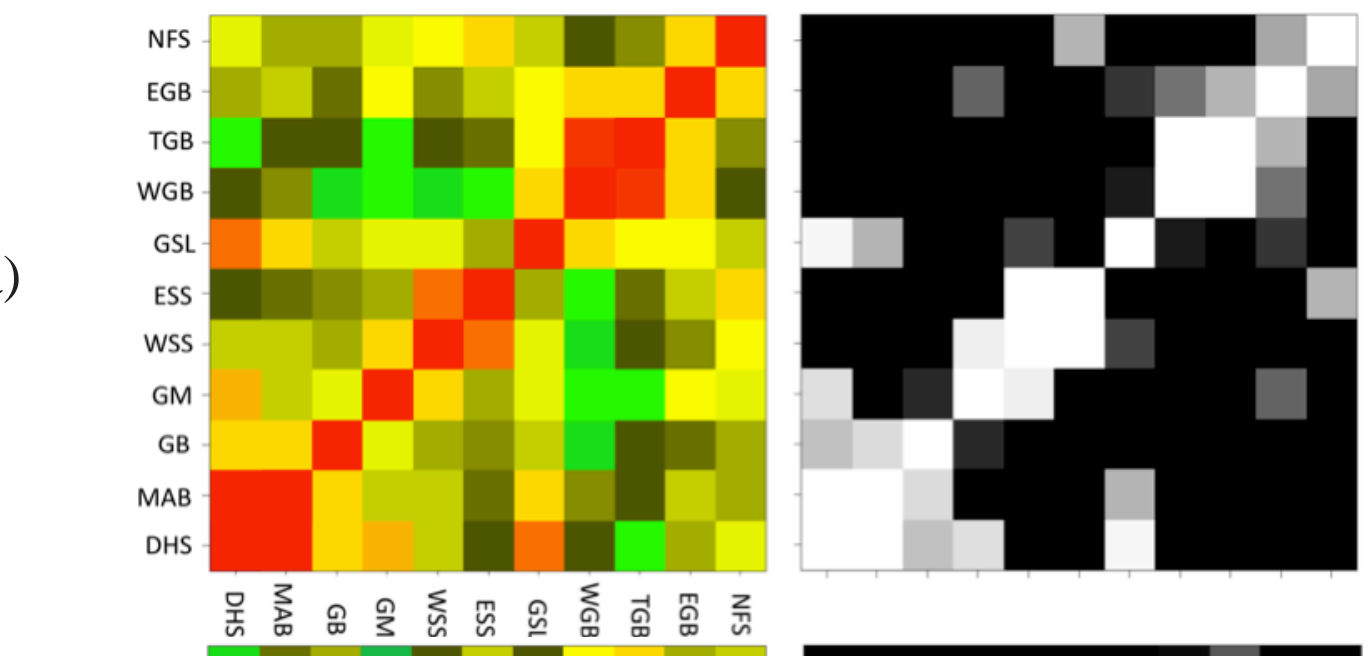

b)
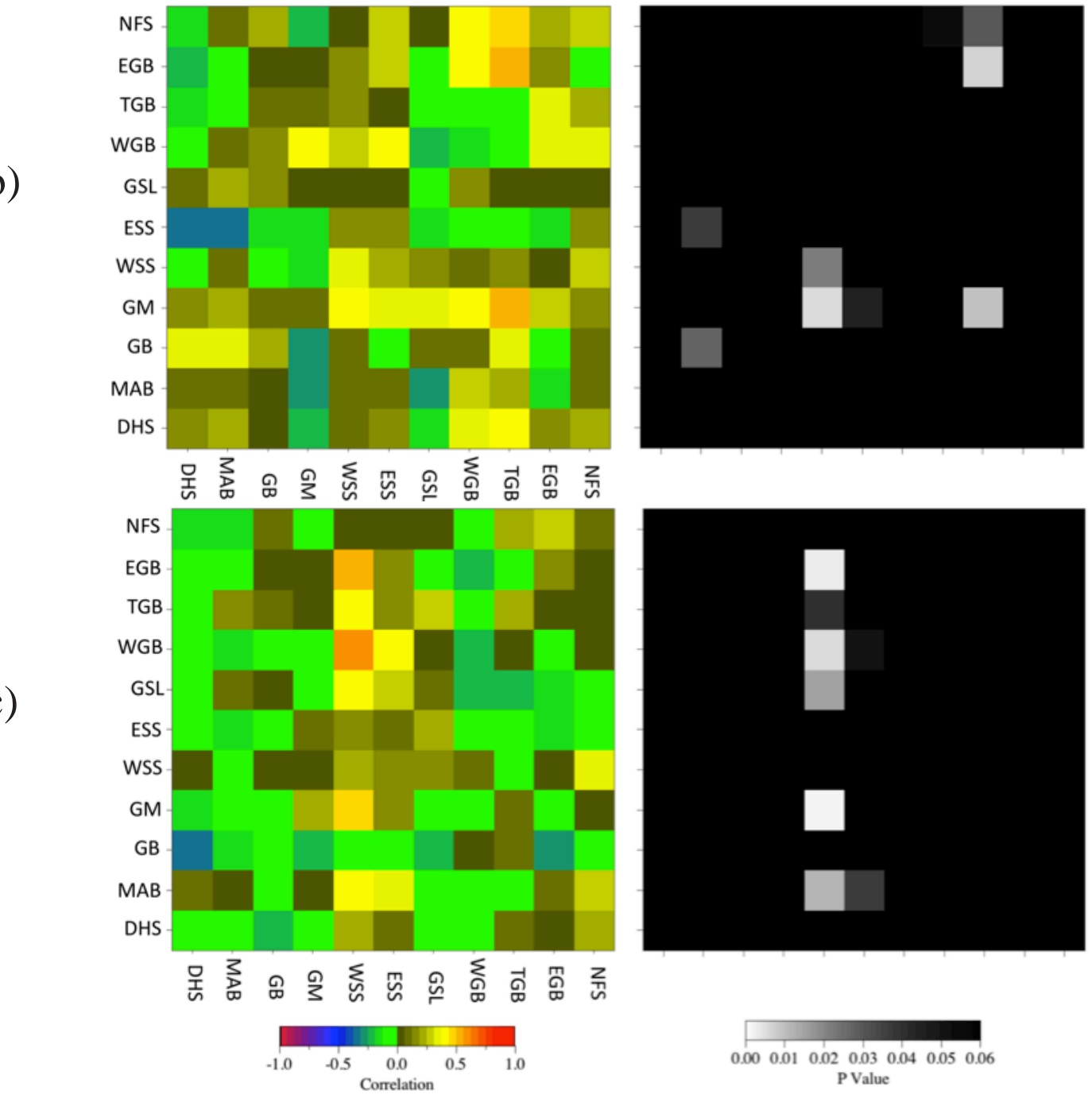

c)

$\begin{array}{lllllllllllllll}0.00 & 0.01 & 0.02 & 0.03 & 0.04 & 0.05 & 0.06\end{array}$

Figure 10. Cross-correlation between annual mean NSS residuals given in Figure 10 across all 11 sub-regions, along with p values for: a) 0-year lag, b) 1-year lag, and c) 2-year lag. 


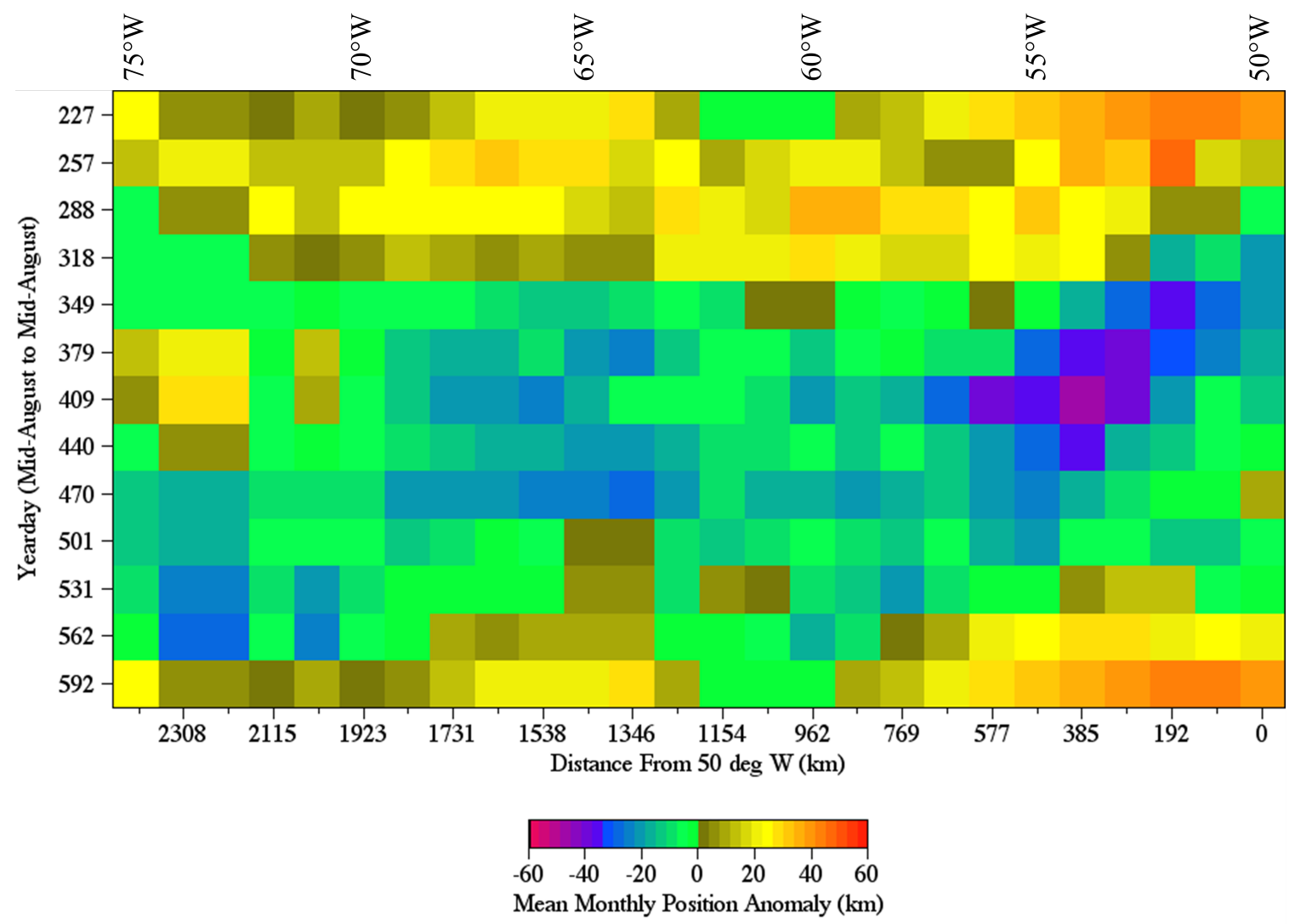

Figure 11. Long-term, 41-year (1973-2013) annual cycle of monthly mean (August to August) SBF position anomalies computed along 26 longitude lines from $50^{\circ}$ to $75^{\circ} \mathrm{W}$. Negative (positive) anomalies indicate offshore (onshore) SBF positions relative to the global mean SBF position given in Figure 4. 


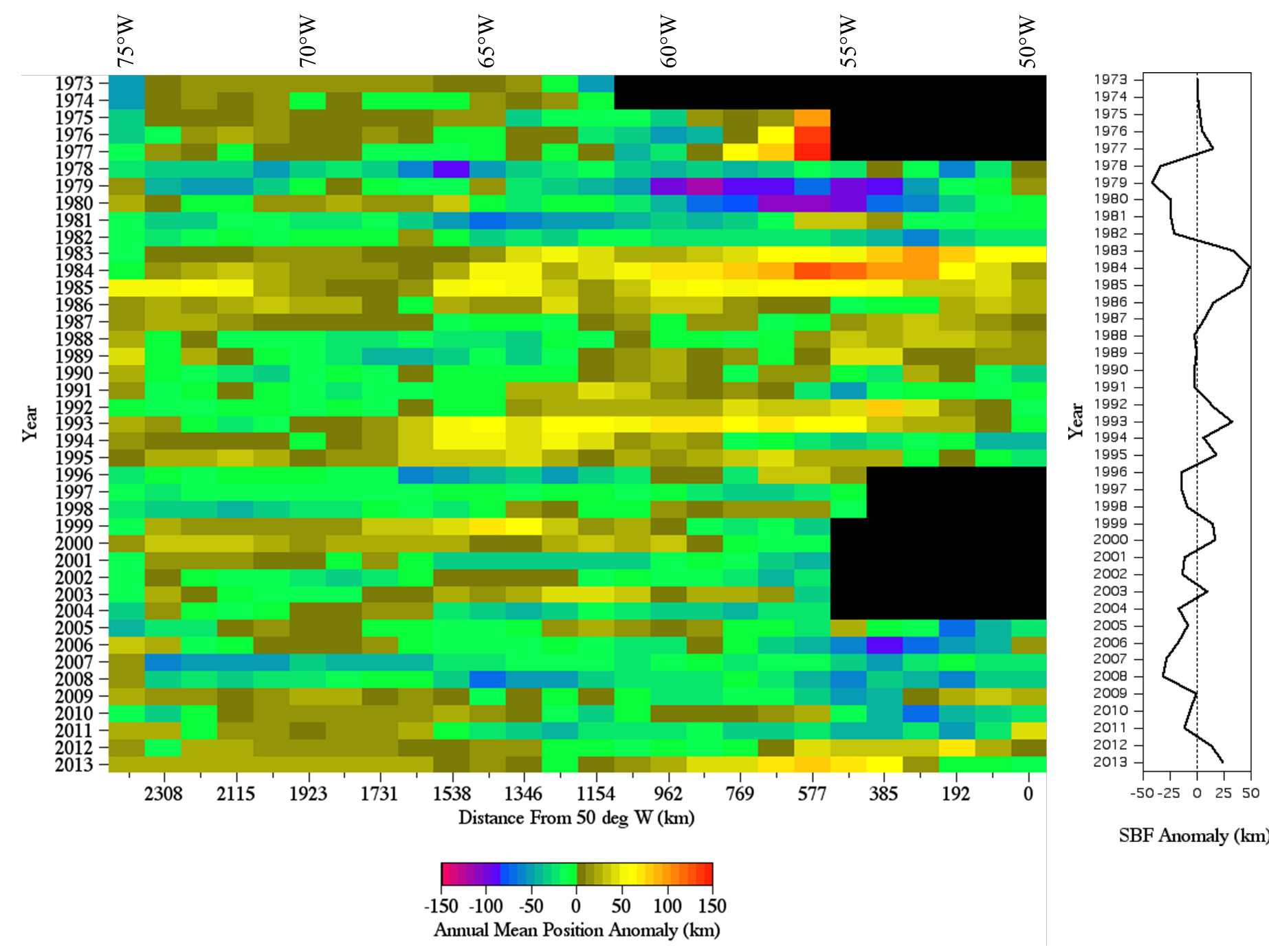

Figure 12. Left panel: Long-term, 41-year (1973-2013) inter-annual variability (IAV) of annual mean SBF position anomalies computed along 26 longitude lines from $50^{\circ}$ to $75^{\circ} \mathrm{W}$ after removal of the seasonal variability. Negative (positive) values indicate offshore (onshore) SBF position anomalies. Black regions are missing data. Right panel: SBF anomaly averaged along all longitudes from $50^{\circ}$ to $75^{\circ} \mathrm{W}$. 

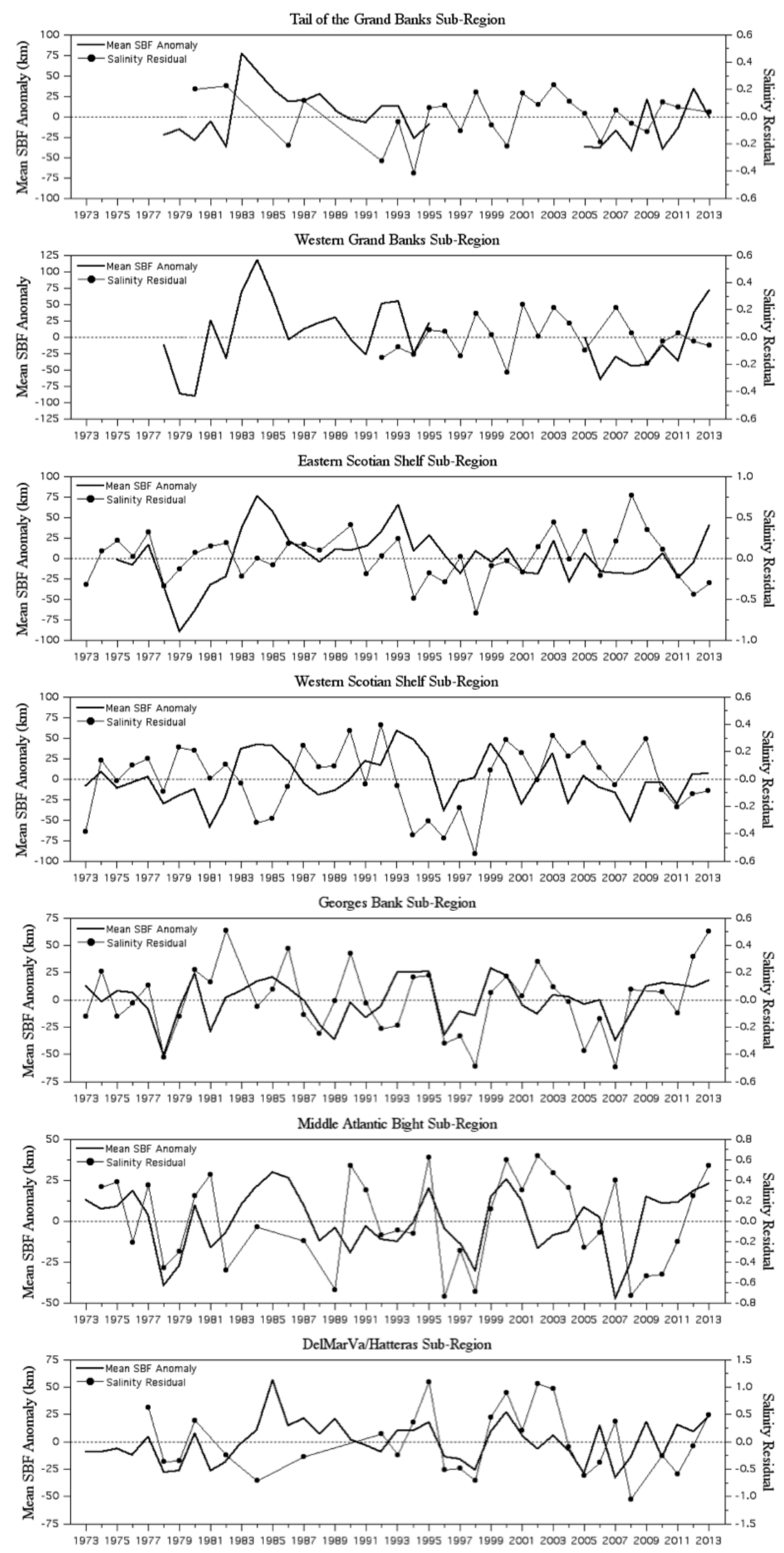

Year

Figure 13. Annual mean SBF position anomalies and annual mean NSS residuals for 7 subregions for the 1973-2013 study period. Missing years signify insufficient data available. 


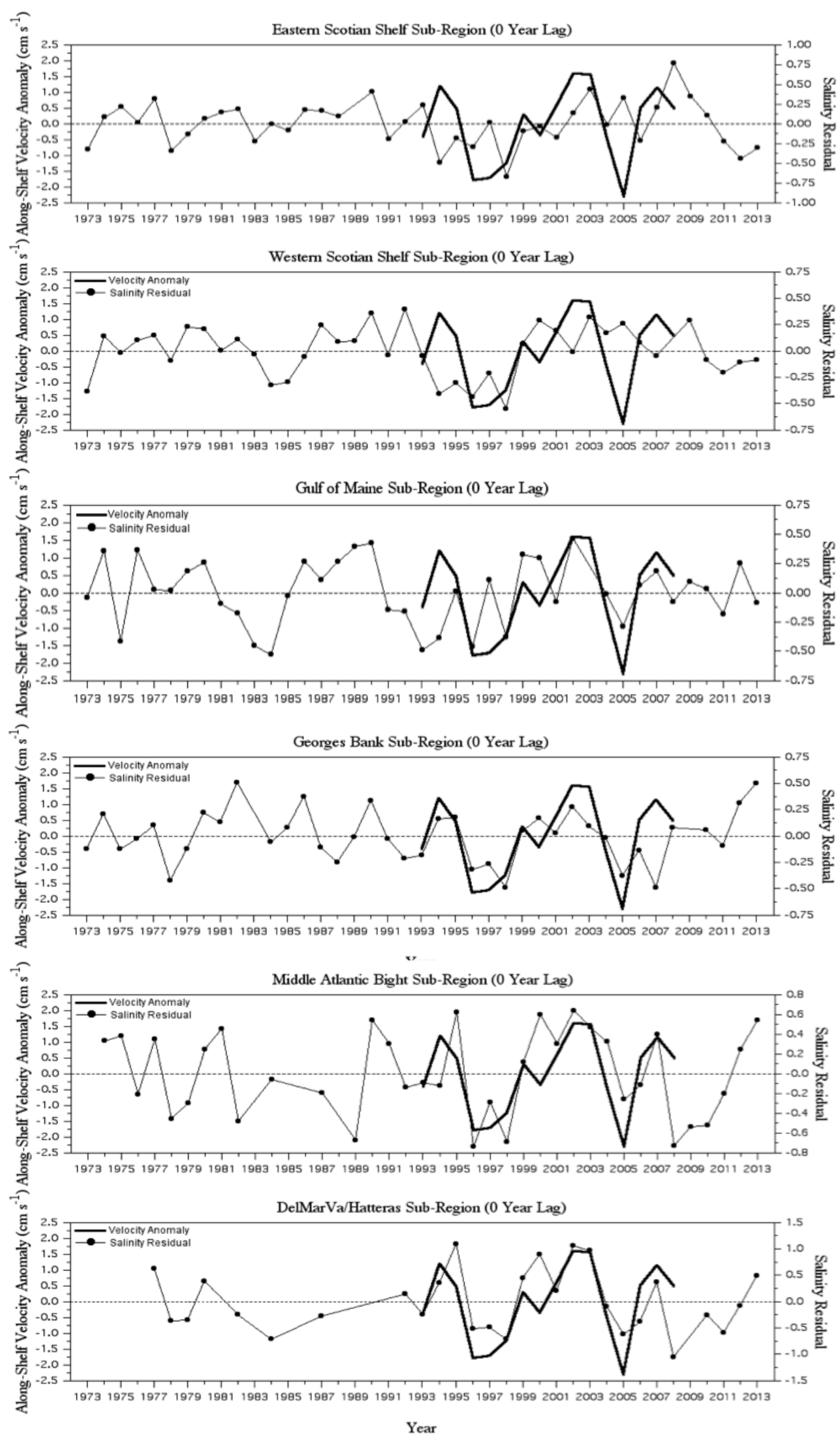

Figure 14. Annual mean along-shelf velocity $(v)$ anomalies from 1993-2008 along satellite altimeter section S1 (see Fig. 4) from Li et al. (2014) and annual mean NSS residuals for 6 subregions for the 1973-2013 study period. Missing years signify insufficient data available. 


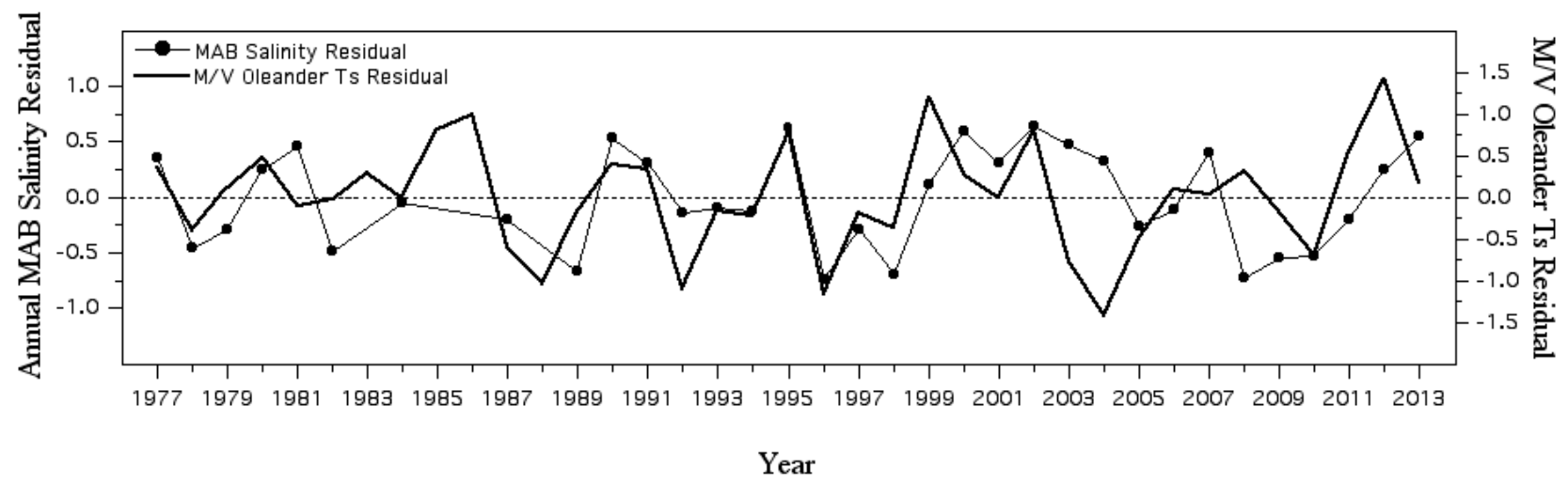

Figure 15. Annual mean CMV Oleander temperature residuals $\left(T_{s}{ }^{\prime}\right)$ from 1977-2013 along the Oleander section (see Fig. 4) as described by Forsyth et al. (2015) and annual mean NSS residuals for the MAB sub-region. Missing years signify insufficient data available. 




Figure 16. Annual mean composite coastal sea level anomalies from 12 tide gauges for 1970-2012 as described by Andres et al. (2013) and annual mean NSS residuals for the MAB sub-region. Missing years signify insufficient data available. 


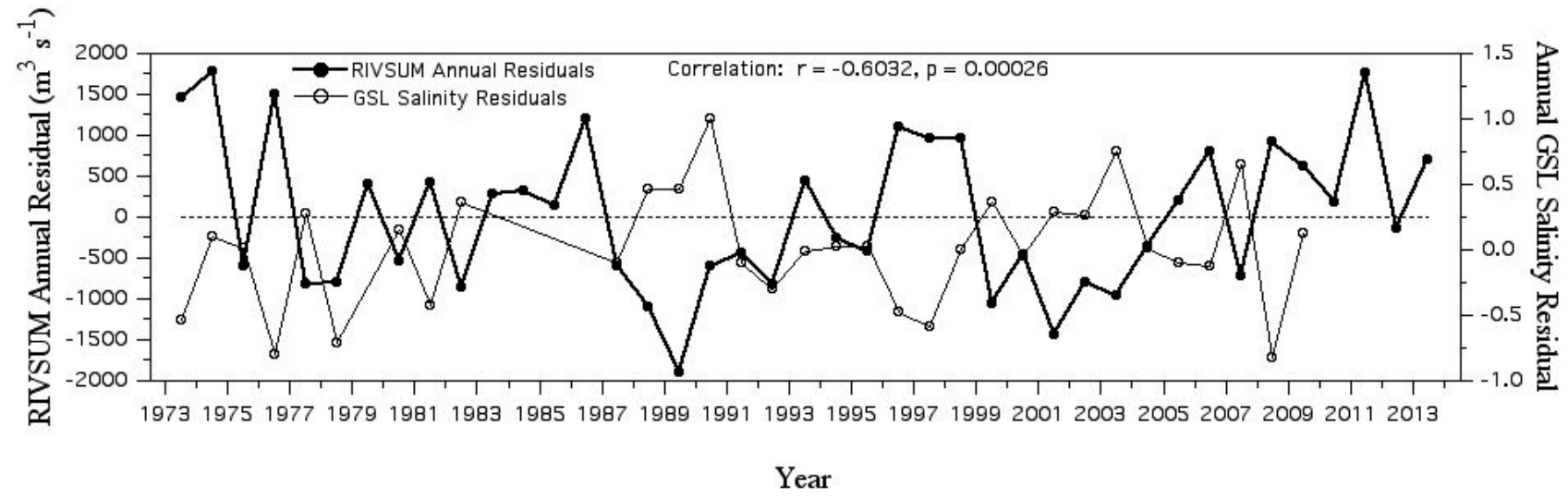

Figure 17. Annual mean RIVSUM discharge residuals and annual mean NSS residuals for the GSL sub-region for 1973-2013. Missing years signify insufficient data available. 


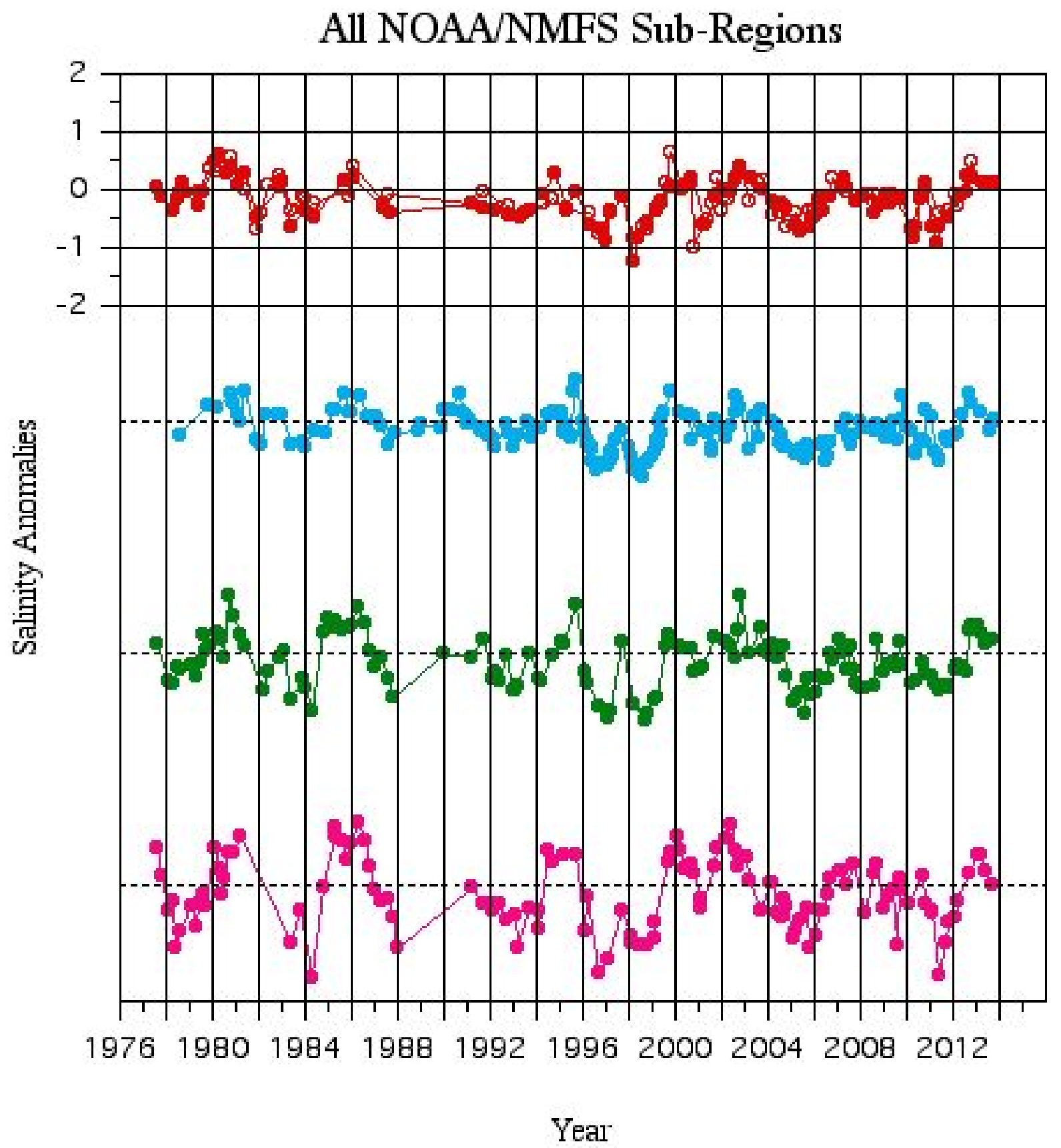

Figure 18. Surface salinity anomalies computed from individual NOAA/NMFS cruises (from Fig. 10) for the nominal 1977-2013 period, (MARMAP, 1977-1987; spring and fall survey cruises, and EcoMon data through 2013) computed using the 1977-1987 MARMAP baseline period for Gulf of Maine east (red solid symbols) and Gulf of Maine west (red open symbols), Georges Bank (cyan), Middle Atlantic Bight north (green) and Middle Atlantic Bight south (magenta). 

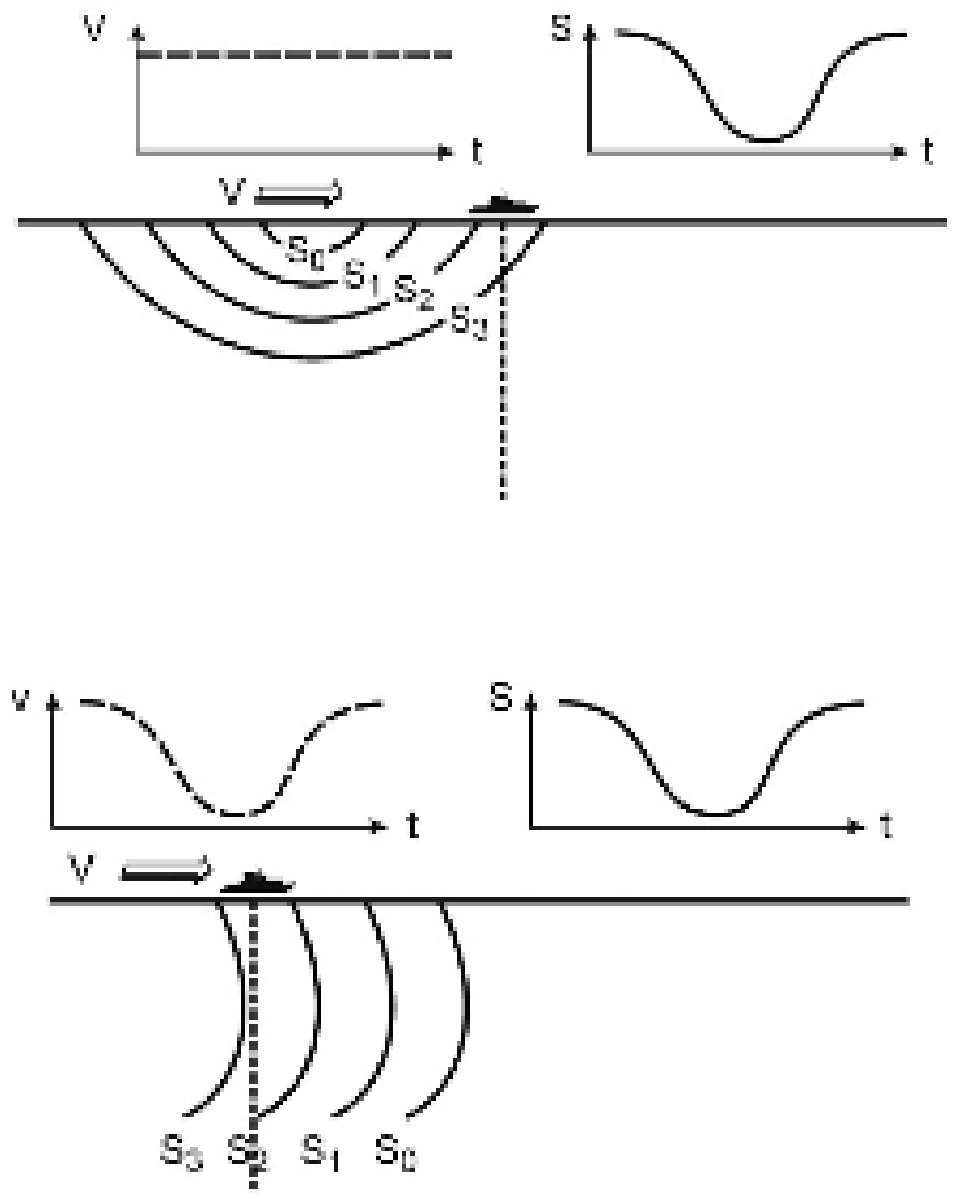

Figure 19. Two different salinity anomaly mechanisms, which produce identical results (After Sundby and Drinkwater (2007)). Top panel: "patch advection" of a near-surface low-salinity pool of water passing through a fixed hydrographic station; Bottom Panel: "flux variation in a salinity gradient” where a spatial salinity gradient is advected to and fro by a change in velocity (flux) at a fixed hydrographic station. 

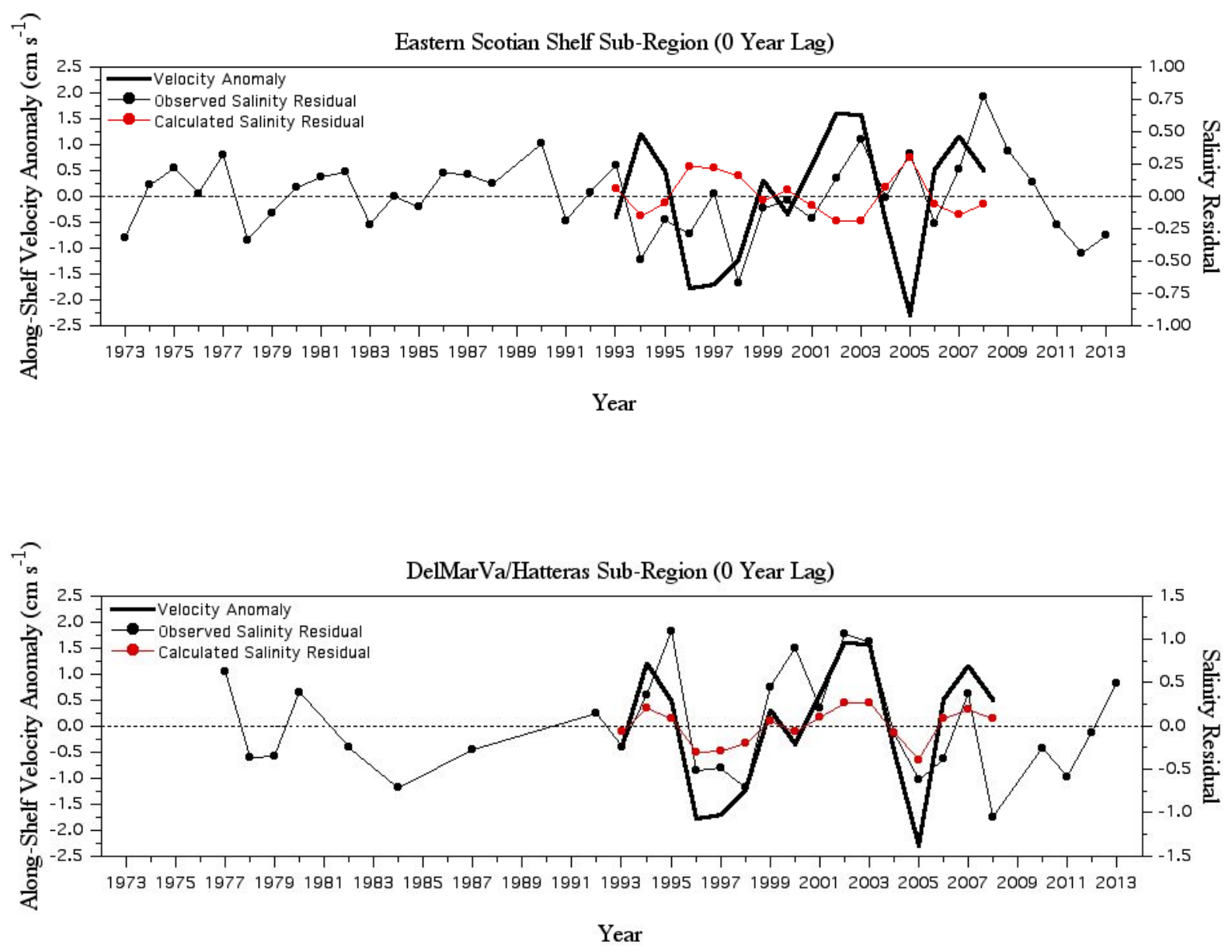

Figure 20. Observed NSS residuals (black solid dots) compared with calculated NSS residuals (red solid dots) using the "flux variation" model of Sundby and Drinkwater (2007) and equation 2 for the ESS sub-region (top panel) and the DHS sub-region (bottom panel). Also shown are the annual mean along-shelf velocity ( $v$ ) anomalies (heavy line) from 1993-2008 along satellite altimeter section S1 (see Fig. 4) from Li et al. (2014). 
Table 1. River Gauging Station Identifiers and Station Locations

\begin{tabular}{|c|c|c|c|}
\hline River & USGS Gauge Station & Latitude (N) & Longitude (W) \\
\hline St. John & 01014000 & $47^{\circ} 17^{\prime} 00^{\prime}$ & $68^{\circ} 35^{\prime} 07^{\prime}$ \\
\hline St. Croix & 01021000 & $45^{\circ} 08^{\prime} 13^{\prime}{ }^{\prime}$ & $67^{\circ} 19^{\prime} 05^{\prime}$ \\
\hline Merrimack & 01100000 & $42^{\circ} 38^{\prime} 45^{\prime}$, & $71^{\circ} 17^{\prime} 56^{\prime}$ \\
\hline Hudson & 01358000 & $42^{\circ} 45^{\prime} 08^{\prime}$, & $73^{\circ} 41^{\prime} 20^{\prime}$ \\
\hline Delaware & 01463500 & $40^{\circ} 13^{\prime} 18^{\prime}$, & $74^{\circ} 46^{\prime} 41^{\prime}$ \\
\hline Susquehanna & 01578310 & $39^{\circ} 39^{\prime} 28^{\prime}$ & $76^{\circ} 10^{\prime} 28^{\prime}$ \\
\hline Potomac & 01646502 & $38^{\circ} 56^{\prime} 58^{\prime}$, & $77^{\circ} 07^{\prime} 40^{\prime \prime}$ \\
\hline RIVSUM & ${ }^{1}$ See below & & \\
\hline
\end{tabular}

${ }^{1}$ RIVSUM is the sum of the discharge from the major St. Lawrence and Saguenay Rivers, plus the sum of the more minor Betsiamites, Outardes and Manicouagan Rivers. Data supplied by the Canadian Hydrographic service and the St. Lawrence Global Observatory. 
Table 2. Shelf Sub-Region NSS Statistics

Global Mean Salinities, Minima and Maxima From Fitted Annual Cycle, and the Trend Model Used, Long-Term Salinity Trend, and Mean Squared Error (mse)

Relative to the Fitted Trend Model

\begin{tabular}{|c|c|c|c|c|c|c|}
\hline Sub-Region & Mean & Min & Max & Model & $\Delta \mathbf{S} / \Delta \mathbf{t}\left(\mathbf{y}^{-1}\right)$ & mse \\
\hline NFS & 32.02 & 30.89 & 32.80 & Linear & +0.011 & 0.039 \\
\hline EGB & 32.34 & 31.77 & 32.74 & Mean & - & 0.029 \\
\hline TGB & 32.35 & 32.04 & 32.61 & Mean & - & 0.031 \\
\hline GSB & 31.99 & 31.64 & 32.38 & ${ }^{1}$ Quadr & $+0.022,-0.006$ & 0.020 \\
\hline ESS & 30.49 & 29.13 & 31.63 & Mean & - & 0.192 \\
\hline WSS & 31.50 & 31.08 & 31.77 & Linear & -0.007 & 0.058 \\
\hline GM & 32.12 & 31.58 & 32.52 & Linear & -0.014 & 0.079 \\
\hline GB & 32.44 & 32.08 & 32.72 & Linear & -0.011 & 0.064 \\
\hline MAB & 32.08 & 30.77 & 32.82 & Mean & - & 0.193 \\
\hline DHS & 32.72 & 31.44 & 33.67 & Linear & +0.024 & 0.362 \\
\hline
\end{tabular}

${ }^{1}$ An increase through 2007, computed between 1980 and 2007, decreasing thereafter, computed between 2007 and 2013.

${ }^{2}$ An increase through 1992, computed between 1973 and 1992, decreasing thereafter, computed between 1992 and 2013. 
Table 3. SBF and NSS Cross-Correlations for 7 Shelf Sub-Regions

Correlation coefficient (p value) computed between $\mathrm{N}$ annual mean NSS residuals and spatially-averaged SBF position anomalies across assigned SBF longitudes from 1973-2013

Significant correlation values $(\mathrm{p} \leq 0.05)$ are shown in bold.

\begin{tabular}{|c|c|c|c|}
\hline Sub-Region & Assigned SBF Longitudes & $\mathbf{N}$ & $\begin{array}{c}\mathbf{r} \\
\text { (p-value) }\end{array}$ \\
\hline TGB & $50^{\circ}-53^{\circ} \mathrm{W}$ & 16 & $\begin{array}{c}0.2492 \\
(0.3522)\end{array}$ \\
\hline
\end{tabular}




\begin{tabular}{|c|c|c|c|}
\hline WGB & $54^{\circ}-56^{\circ} \mathrm{W}$ & 12 & $\begin{array}{c}0.2202 \\
(0.4915)\end{array}$ \\
\hline ESS & $57^{\circ}-61^{\circ} \mathrm{W}$ & 38 & $\begin{array}{c}0.0092 \\
(0.9560)\end{array}$ \\
\hline WSS & $62^{\circ}-65^{\circ} \mathrm{W}$ & 40 & $\begin{array}{c}0.1304 \\
(0.4232)\end{array}$ \\
\hline GB & $66^{\circ}-69^{\circ} \mathrm{W}$ & 39 & $\begin{array}{c}0.4817 \\
(0.0019)\end{array}$ \\
\hline МAB & $70^{\circ}-72^{\circ} \mathrm{W}$ & 36 & $\begin{array}{c}0.2238 \\
(0.1895)\end{array}$ \\
\hline DHS & $73^{\circ}-75^{\circ} \mathrm{W}$ & 28 & $\begin{array}{c}0.4147 \\
(0.0282)\end{array}$ \\
\hline
\end{tabular}


Table 4. Velocity ( $v$ ) Anomaly and NSS Cross-Correlations for 6 Shelf Sub-Regions Correlation coefficient (p value) computed between $\mathrm{N}$ annual mean NSS residuals and along-shelf velocity anomalies measured at section S1 between 1993 and 2008 Significant correlation values $(\mathrm{p} \leq 0.05)$ are shown in bold.

\begin{tabular}{|c|c|c|}
\hline Sub-Region & $\mathbf{N}$ & $\begin{array}{c}\mathbf{r} \\
\text { (p-value) }\end{array}$ \\
\hline \multirow{2}{*}{ ESS } & 16 & $\begin{array}{c}0.1677 \\
(0.5348)\end{array}$ \\
\hline \multirow{2}{*}{ WSS } & 15 & 0.1983 \\
& & $(0.4787)$ \\
\hline
\end{tabular}




\begin{tabular}{|c|c|c|}
\hline GM & 15 & $\begin{array}{c}0.4587 \\
(0.0855)\end{array}$ \\
\hline \multirow{2}{*}{ GB } & 16 & $\mathbf{0 . 6 0 9 6}$ \\
& & $\mathbf{( 0 . 0 1 2 2 )}$ \\
\hline \multirow{2}{*}{ MAB } & 16 & $\mathbf{0 . 5 7 8 9}$ \\
& & $\mathbf{( 0 . 0 1 8 8 )}$ \\
\hline \multirow{2}{*}{ DHS } & 16 & $\mathbf{0 . 6 3 1 2}$ \\
& & $\mathbf{( 0 . 0 0 8 7 )}$ \\
\hline
\end{tabular}


Table 5. Cross-Correlations for the Middle Atlantic Bight (MAB) Sub-Region Correlation coefficient (p value) computed between Coastal Sea Level Anomaly (CSLA), $M / V$ Oleander transect temperature residuals $\left(T_{s}^{\prime}\right)$, and MAB NSS residuals (MAB_S) from this study at five different lags of $-2,-1,0,+1$, and +2 years.

Second correlate lags the first correlate by the specified years.

Significant correlation values $(\mathrm{p} \leq 0.05)$ are shown in bold.

\begin{tabular}{|c|c|c|c|c|c|}
\hline Correlates & Lag -2 & Lag -1 & Lag 0 & Lag +1 & Lag +2 \\
\hline CSLA & -0.1350 & -0.2465 & -0.5228 & -0.1907 & -0.1535 \\
\hline vs. & $(0.5154)$ & $(0.1814)$ & (n nn?1) & $(0.2958)$ & $(0.4096)$ \\
\hline MAB_S & & & & & \\
\hline CSLA & 0.0231 & -0.0 .0253 & -0.1540 & 0.1456 & 0.5555 \\
\hline vs. & $(0.8966)$ & (0.8851) & (0.3699) & $(0.3967)$ & $(00005)$ \\
\hline $\mathbf{T}_{\mathrm{s}}$ & & & & & \\
\hline $\mathbf{T}_{\mathrm{s}}$ & 0.0598 & 0.3041 & 0.3918 & -0.3422 & -0.3141 \\
\hline vs. & $(0.7494)$ & $(0.0906)$ & $(0,0241)$ & $(0.0552)$ & $(0.0853)$ \\
\hline MAB_S & & & & & \\
\hline
\end{tabular}

